\title{
Fluorescent biological aerosol particles measured with the Waveband Integrated Bioaerosol Sensor WIBS-4: laboratory tests combined with a one year field study
}

\author{
E. Toprak and M. Schnaiter \\ Institute for Meteorology and Climate Research - Atmospheric Aerosol Research, Karlsruhe Institute of Technology, \\ Karlsruhe, Germany \\ Correspondence to: E. Toprak (emre.toprak@kit.edu)
}

Received: 19 June 2012 - Published in Atmos. Chem. Phys. Discuss.: 18 July 2012

Revised: 6 November 2012 - Accepted: 22 November 2012 - Published: 10 January 2013

\begin{abstract}
In this paper bioaerosol measurements conducted with the Waveband Integrated Bioaerosol Sensor mark 4 (WIBS-4) are presented. The measurements comprise aerosol chamber characterization experiments and a one-year ambient measurement period at a semi-rural site in South Western Germany. This study aims to investigate the sensitivity of WIBS-4 to biological and non-biological aerosols and detection of biological particles in the ambient aerosol. Several types of biological and non-biological aerosol samples, including fungal spores, bacteria, mineral dust, ammonium sulphate, combustion soot, and fluorescent polystyrene spheres, were analyzed by WIBS- 4 in the laboratory. The results confirm the sensitivity of the ultraviolet light-induced fluorescence (UV-LIF) method to biological fluorophores and show the good discrimination capabilities of the two excitation wavelengths/detection wavebands method applied in WIBS-4. However, a weak cross-sensitivity to non-biological fluorescent interferers remains and is discussed in this paper.

All the laboratory studies have been undertaken in order to prepare WIBS-4 for ambient aerosol measurements. According to the one-year ambient aerosol study, number concentration of fluorescent biological aerosol particles (FBAP) show strong seasonal and diurnal variability. The highest number concentration of FBAP was measured during the summer term and decreased towards the winter period when colder and drier conditions prevail. Diurnal FBAP concentrations start to increase after sunset and reach maximum values during the late night and early morning hours. On the other hand, the total aerosol number concentration was almost always higher during daytime than during nighttime and a sharp de-
\end{abstract}

crease after sunset was observed. There was no correlation observed between the FBAP concentration and the meteorological parameters temperature, precipitation, wind direction and wind speed. However, a clear correlation was identified between the FBAP number concentration and the relative humidity. Humidity-controlled release mechanisms of some fungal spore species are discussed as a possible explanation.

\section{Introduction}

Primary biological aerosol particles (PBAP) basically consist of particles that are derived from living organisms, including microorganisms, dispersal units and fragments of all varieties of living things and they can be either dead or alive (Despres et al., 2012). This subset of the atmospheric aerosols contains fungi, viruses, bacteria, spores, pollen and animal and plant debris. PBAP are potentially important for cloud formation processes because they have the potential to act as effective cloud condensation nuclei (CCN) (Petters and Kreidenweis, 2007) and heterogeneous ice nuclei (IN) at temperatures as warm as $-2^{\circ} \mathrm{C}$ (Diehl et al., 2001, 2002). They affect public health and play important roles in further atmospheric processes (Pöschl, 2005). There are not enough studies yet about the abundance of PBAP in the atmosphere, their release and dispersal mechanisms, and their role in atmospheric aerosolcloud processes.

Previous studies that have been conducted over the past $10 \mathrm{yr}$ have shown that atmospheric PBAP concentrations are highly variable and strongly related to the biological 
activity in the measurement area (Matthias-Maser et al., 1995; Matthias-Maser and Jaenicke, 1995). Because of the lack of online measurement systems, the PBAP budgets have been estimated by mainly using proxy measurements such as mannitol and organic carbon (Elbert et al., 2007). Electron microscopy investigations combined with EDX (energydispersive X-ray spectroscopy) analysis of atmospheric samples have revealed a PBAP to total coarse mode aerosol particle ratio of $23.7 \%$ in an urban/rural area and $19.5 \%$ at a remote continental area, which correspond to PBAP number concentrations of 1.9 and $0.22 \mathrm{~cm}^{-3}$, respectively (MatthiasMaser et al., 2000). It should be noted that these numbers refer only to a specific size range. For instance, Matthias-Maser et al. (2000) analyzed and reported PBAP in the size range of $0.2 \mu \mathrm{m}<r<2 \mu \mathrm{m}$. On the other hand, Elbert et al. (2007) reported the number concentrations of fungal spores with sizes up to $20 \mu \mathrm{m}$. Therefore, direct comparison of our findings with previously published studies may not be possible. For the reader, we would like to make it clear that the reported numbers may correspond to different ratios. Gruber et al. (1999) collected both marine and continental air samples on Helgoland, Germany, and on board an aircraft over the North Sea. They analyzed concentration and the chemical composition of aerosol in marine and continental air and found that the fraction of biological particles in the total aerosol load is around $20 \%$ for continental areas, while in marine air this value was determined to be around $9 \%$. Jaenicke et al. (2007) found coarse mode PBAP number concentrations between $1-3 \mathrm{~cm}^{-3}(3-50 \%)$ in Mainz and between $0.1-1 \mathrm{~cm}^{-3}(15-30 \%)$ at Lake Baikal.

Yadav et al. (2004) studied bacterial colonization and report phyllosphere bacterial concentrations of less than the limit of detection, up to $1.4 \times 10^{7}$ cells $^{-1}$. Another study gives average population densities of these epiphytic bacteria between $10^{4}$ and $10^{8}$ cells $\mathrm{cm}^{-2}$ (Morris and Klinkel, 2002). Christner et al. (2008) examined the DNA-containing cell concentrations and ice nuclei (IN) properties of 19 fresh snowfalls $\left(>-10^{\circ} \mathrm{C}\right)$ and report cell concentrations between $1.5 \times 10^{4}$ and $5.4 \times 10^{6}$ cells $\mathrm{L}^{-1}$ for melted snow water. The differences between the reported concentrations demonstrate the difficulty in estimating total concentrations of PBAP. Sanchez-Ochoa et al. (2007) found airborne plant debris concentrations between $0.03-0.36 \mu \mathrm{g} \mathrm{m}^{-3}$. The bacterial mass concentration was reported around $0.1 \mu^{-3} \mathrm{~m}^{-3}$ (Bauer et al., 2002; Burrows et al., 2009).

In addition, there are studies dealing with the release and detection of fungal spores. Bauer et al. (2002) for instance examined the number concentration of fungi at a continental background in the Austrian Alps and reported fungal spore concentrations around $7.3 \times 10^{2}$ spores $\mathrm{m}^{-3}$. Gilbert and Reynolds (2005) counted fungal spores in a tropical forest and reported diurnal concentrations ranging from $\sim 10^{2}$ spores $\mathrm{L}^{-1}$ to $\sim 10^{3}$ spores $\mathrm{L}^{-1}$. Wu et al. (2004) reported a total fungal spore concentration of 28 spores $\mathrm{L}^{-1}$ in southern Taiwan and added that increasing daily temperature and rela- tive humidity is associated with rising basidiospore levels in the atmosphere. They also concluded that increasing basidiospore levels in sandstorm days are mainly allocable to the dust event in that area.

Fungal spores are indeed a significant fraction of the atmospheric PBAP (Womiloju et al., 2003; Elbert et al., 2007; Bauer et al., 2008; Crawford et al., 2009). Basidiomycota (BMC) and Ascomycota (AMC), which can release their spores according to active and passive mechanisms and have higher abundances at night, are one of the most abundant classes in fungi. This class of fungal spores comprises rusts, smuts and most mushroom forming fungi that produce a diverse array of fruiting bodies (Fröhlich-Nowoisky et al., 2009, 2012). The abundance of fungal spores shows differences due to the environmental factors such as measurement location, season, measurement time and weather conditions (Elbert et al., 2007). The release of wet, actively-discharged $\mathrm{BMC}$ and AMC appears to be correlated to the relative humidity instead of precipitation (Hirst, 1953; Gregory and Hirst, 1957; De Antoni Zoppas et al., 2006). Among these, diversity of BMC is found to be greater than that of AMC in Germany (Fröhlich-Nowoisky et al., 2012).

The online methods developed in response to bio-warfare agents have made the detection of bioaerosols from the ambient atmosphere possible (Pinnick et al., 1998; Hill et al., 1999, 2001). The Ultraviolet Aerodynamic Particle Sizer (UV-APS) is the first commercially available instrument able to detect bioaerosols (Hairston et al., 1997; Brosseau et al., 2000). Huffman et al. (2010) gave an overview of the abundance of FBAP in Mainz, Germany, by using the UV-APS. They analyzed the particles with an aerodynamic particle size $1.0 \mu \mathrm{m}<D_{\mathrm{a}}<20 \mu \mathrm{m}$ and found that FBAP size distribution had shown a strong diurnal cycle (at around 08:00 LT) with a dominant peak around 3-4 $\mathrm{mm}$, which could be attributed to fungal spores or agglomerated bacterial cells. They also reported the highest number concentration in September between $8 \times 10^{3}$ and $1.2 \times 10^{4} \mathrm{~L}^{-1}$ for total aerosol and around $8.5 \times 10^{2} \mathrm{~L}^{-1}$ for fluorescent particles. Average FBAP number and mass concentrations were reported to be around $27 \mathrm{~L}^{-1}$ and $1.3 \mu \mathrm{g} \mathrm{m}^{-3}$, respectively. Gabey et al. (2010, 2011) used the Waveband Integrated Bioaerosol Sensor mark 3 (WIBS-3) to measure fluorescent biological aerosol particles in a tropical rainforest and compared the results with equivalent measurements at an urban area in Manchester. In Borneo, they found the minimum and maximum FBAP number concentrations in the understory to be $50-100 \mathrm{~L}^{-1}$ late in the morning and $4 \times 10^{3} \mathrm{~L}^{-1}$ in mid-afternoon. The FBAP number concentrations between midnight and sunrise were reported to be between $10^{3}-2.5 \times 10^{3} \mathrm{~L}^{-1}$. On the other hand, a strong fluctuation was seen for the above canopy FBAP number concentrations, which were reported to be 50$100 \mathrm{~L}^{-1}$ during daytime and $200-400 \mathrm{~L}^{-1}$ at night. They also attributed these strong FBAP fluctuations to the release of fungal spores below the canopy and appeared to be linked to the elevated relative humidity of the medium. 
In this paper, we present online measurements of ambient FBAP by using the latest version of the WIBS instrument suite (WIBS-4), which is based on the UV light-induced fluorescence (UV-LIF) method. To our knowledge this is the first online FBAP study that covers a complete seasonal cycle. Although previous studies by Gabey et al. (2010, 2011) and Huffman et al. (2010) measured online ambient FBAP concentrations, their studies did not provide any information about the seasonal behavior of the biological aerosol. Gabey et al. (2010) sampled the fluorescent biological aerosol particles for 10.5 days (from 19 April to 3 May 2008) and for 75 h (from 18-23 July 2008). Gabey et al. (2011) collected fluorescence data from 4-21 December 2009. Huffman et al. (2010) collected the ambient data from 3 August to 4 December 2006. Our data give an insight on how the PBAP concentration differs in time and also gives first correlations of the PBAP budget with the meteorological conditions. We found an especially significant correlation of the FBAP concentration with the relative humidity. Our results contribute to the recent discussions on the role of PBAP for atmospheric processes and might be a useful data set for the development of new PBAP emission parameterizations for atmospheric aerosol and cloud models.

\section{Experimental methods}

The UV-LIF method is used in this study for the discrimination of non-biological aerosol from biological aerosol particles (Pinnick et al., 1995; Hairston et al., 1997; Eversole et al., 2001; Ho, 2002). The method is focused on detecting the fluorescence signals from common amino acids like tryptophan, phenylalanine and tyrosine and also from nicotinamide adenine dinucleotide (NADH), which is the metabolic product of bacteria. Among the 20 amino acids, these three are the only ones that can produce enough intrinsic fluorescence after being treated by UV light. Tryptophan is the only amino acid that shows fluorescence emission between $300-450 \mathrm{~nm}$ (excitation at $280 \mathrm{~nm}$ ) and its emission signal is not absorbed by other species (Pan et al., 2007; Pöhlker et al., 2012). NADH is another bio-molecule which is ubiquitous among living organisms with a fluorescence emission between 400 $600 \mathrm{~nm}$ (excitation at $370 \mathrm{~nm}$, Pöhlker et al., 2012). We will show that the combination of measured fluorescence signals from tryptophan and NADH makes it possible to analyze and differentiate biological aerosol with this method (Healy et al., 2012b).

\subsection{WIBS-4 technical details}

WIBS-3 is a single aerosol particle fluorescence monitor that uses the ultraviolet light-induced fluorescence (UV-LIF) method to detect FBAP (Kaye et al., 2005; Foot et al., 2008; Stanley et al., 2011). WIBS-4 (Healy et al., 2012a, b) incorporates numerous software improvements over previous
WIBS versions as well as a five-fold improvement on fluorescence sensitivity. In principle, WIBS-4 has two filtered xenon lamps that provide two sequential ultraviolet pulses centred at 280 and $370 \mathrm{~nm}$. The xenon lamps are capable of firing at a maximum repetition rate of approximately $125 \mathrm{~Hz}$. This corresponds to a maximum detectable particle concentration of approximately $2 \times 10^{4}$ particles $\mathrm{L}^{-1}$. These ultraviolet pulses are used to excite tryptophan and NADH fluorescence in the particles. Resulting total fluorescence is then measured in three fluorescence channels: the emission following a $280 \mathrm{~nm}$ excitation is recorded in the $310-400 \mathrm{~nm}$ (channel F1, tryptophan) and 420-650 nm (channel F2) wavebands, and a $370 \mathrm{~nm}$ excitation is recorded in the $420-650 \mathrm{~nm}$ waveband (channel F3, NADH). These individual channels record fluorescence intensity for single particles. By using the measured fluorescence data, we can discriminate biological aerosol from the non-biological aerosols. This single particle data may also be analyzed with different methods to gain more information about the nature of the bioaerosols (Robinson et al., 2012). By following Gabey et al. (2010), we also used the combination of $\mathrm{F} 1$ and $\mathrm{F} 3$ for discriminating fluorescent biological aerosol particles (FBAP, ref. Table 1). Due to the high cross-sensitivity of F2 to non-biological aerosols, we preferred using F1 and F3 for discriminating fluorescent biological aerosol particles. According to Gabey (2011), channel F2 could measure tryptophan (which has a relatively weak emission at 410-600 nm) and/or NADH (with weak absorption at $280 \mathrm{~nm}$ ), depending on the relative abundance of each molecule in the sample. It was further concluded that intensity of channel F2 generally correlates more strongly with one of the channels than the other. In light of these findings, we decided to omit channel F2 in this study. As in the previous WIBS instruments, the WIBS-4 version records the optical size and the sphericity in addition to the fluorescence excitation-emission matrix from individual particles collected in the approximate size range $0.5-16 \mu \mathrm{m}$. Owing to possible interference from non-biological fluorescent particles (generally consist of particles $<0.8 \mu \mathrm{m}$ ), we calculated the total $\left(N_{\mathrm{T}}\right)$ and the fluorescent biological aerosol number concentrations $\left(N_{\mathrm{FBAP}}\right)$ for particles in the size range $0.8<D_{\mathrm{p}}<16 \mu \mathrm{m}$. The cross-sensitivity issue is discussed in Sect. 2.2 in detail.

WIBS-4 measures the asymmetry factor (AF) of the particles by combining the forward scattered light collected by a quadrant photomultiplier tube (PMT), (Hirst et al., 2001; Kaye et al., 2007; Gabey et al., 2010). According to this definition, AF is zero for a perfectly spherical particle, while it approaches 100 for a fiber that is oriented with its long axis perpendicular to the incident light direction. It was found by Foot et al. (2008) that for an elongated particle, such a rodshaped substance indeed tends to be aligned parallel to the direction of the sample airflow, i.e. perpendicular to the incident light. In laboratory tests with polystyrene latex (PSL) particles, we have found that due to the detector noise the AF value of real spherical particles is around 8 , with slightly 
Table 1. Definition of abbreviations used in the text.

\begin{tabular}{ll}
\hline Short name & Description \\
\hline TAP & Total aerosol particle (all particles measured by WIBS-4; fluorescent and non-fluorescent \\
FBAP & Fluorescent biological aerosol particle (combination of F1 and F3) \\
NON & Non-fluorescent aerosol particle \\
$N_{\mathrm{T}}$ & Number of all particles measured by WIBS-4 \\
$N_{\mathrm{FBAP}}$ & Number of fluorescent particles in F1 \& F3 \\
$N_{\mathrm{NON}}$ & Number of non-fluorescent particles \\
$\mathrm{F} 1$ & Fluorescence detected in channel F1_280 (excitation at 280 nm, detection 310-400 nm) \\
$\mathrm{F} 2$ & Fluorescence detected in channel F2_280 (excitation at 280 nm, detection 420-650 nm) \\
$\mathrm{F} 3$ & Fluorescence detected in channel F2_370 (excitation at 370 nm, detection 420-650 nm) \\
F1\&F2 & Particles showing fluorescence in channel F1_280 \& F2_280 \\
F2\&F3 & Particles showing fluorescence in channel F2_280 \& F2_370 \\
F1\&F3 & Particles showing fluorescence in channel F1_280 \& F2_370 \\
$N_{\mathrm{F} 1, \mathrm{~F} 2}$ & Number of fluorescent particles in F1\&F2 \\
$N_{F 2, F 3}$ & Number of fluorescent particles in F2\&F3 \\
$N_{\mathrm{F} 1, \mathrm{~F} 3}$ & Number of fluorescent particles in F1\&F3 \\
$W_{\mathrm{S}}$ & Wind speed \\
$D_{\mathrm{p}}$ & Optical particle size \\
\hline
\end{tabular}

$N_{\mathrm{F} 1 \text {,F3 }}$ and $N_{\mathrm{FBAP}}$ correspond to the aerosols that fluoresce in channels F1 and F3. In the laboratory aerosol test section (see Sect. 3.1), we preferred using the term $N_{\mathrm{F} 1, \mathrm{~F} 3}$, since we talk about not only biological but also non-biological aerosols. In the Sect. 3.2, we used the acronym FBAP, which represents fluorescent biological aerosols in the ambient atmosphere.

higher values for particles with diameters at the lower detection limit of the instrument (Fig. 1).

As for other optical particle counters, the WIBS-4 scattering channel is calibrated by using spherical PSL particles of known diameter and refractive index. In the present work the manufacturer's instrument calibration was checked periodically with PSL particles of different size.

The total aerosol flow for WIBS-4 is set to $2.5 \mathrm{~L} \mathrm{~min}^{-1}$. A special aerosol inlet system is used in WIBS-4 in order to generate a confined particle beam through the detection volume. For that, the total aerosol flow is split and the main part is directed through a HEPA filter and then returned to sheath the remaining sample flow in the inlet. In this way a confined sample flow of about $0.23 \mathrm{~L} \mathrm{~min}^{-1}$ is generated by the inlet.

\subsection{Fluorescence threshold for identification of FBAP}

With each UV excitation pulse, the WIBS-4 always records a finite amount of background fluorescence. To distinguish this background from the particle-induced fluorescence signal a threshold is defined. Therefore, the instrument can be operated in a forced trigger mode to measure solely the background fluorescence. In this mode the xenon lamps are fired periodically at approximately $1 \mathrm{~s}$ intervals with no particles present. A minimum 5 min. forced trigger measurement was always performed before starting any measurement.

Background fluorescence intensity in each channel ( $F 1$, F2, and F3) is a combination of the standard deviation of detector noise, the variability of the UV pulse intensities, and the fluorescence induced from aerosol particles escaped from the aerosol flow and deposited on the inner walls of the detection chamber. Following Gabey et al. (2010), the noise threshold is defined as in Eq. (1) and could be altered during data processing. Forced trigger data are marked in the single particle data set. According to Eq. (1), any measured fluorescence signal having intensity above $E_{\text {Threshold }}$ is accepted and recorded as a fluorescent particle.

$E_{\text {Threshold }(i)}=\bar{E}_{i}+3 \sigma_{i}(i=$ fluorescence channels $)$

For the one year ambient operation of WIBS-4, the variability of the background fluorescence signals of the individual channels is shown in Fig. 2. From these measurements the mean background signals $\bar{E}_{i}$ and standard deviations $\sigma_{i}$ were determined for the three fluorescence channels as $39.02 \pm 1.92$ for F1_280, $6.33 \pm 2.82$ for FL2_280, and $37.84 \pm 4.48$ for FL2_370, in arbitrary units. Among other fluorescence channels, we observed higher variability on channel F3. Stability of the power of UV lamps was also checked, and despite a slight increase of Xe-280 $(\sim 12.5 \%)$ and $\mathrm{Xe}-370(\sim 8 \%)$ intensities with time, neither sudden increase nor decrease was observed.

In the UV-LIF method approximately $1 \%$ of nonfluorescent particles are misclassified as fluorescent, but an unknown number of fluorescent particles inevitably go undetected through the pre-defined threshold levels of the instrument (Gabey et al., 2010). Moreover, there is another class of aerosol that consists of substances that are able to fluoresce, despite being non-biological in nature, which are a well-known interference to UV-LIF detection. Since they produce high fluorescence intensities on different channels, 


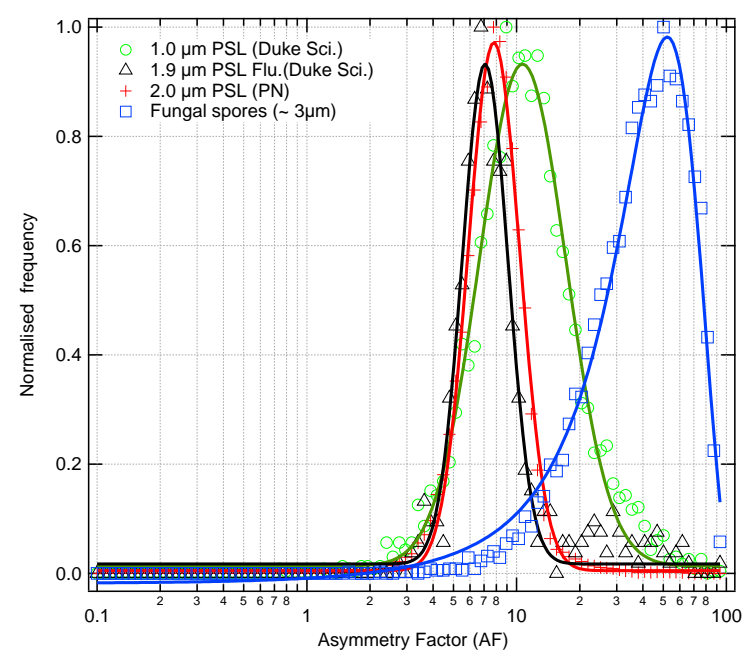

Fig. 1. Asymmetry factor (AF) plot for PSL particles and penicillium notatum type of fungal spores. The fungal spores were supplied from the Swedish company Allergon (Allergon AB, Sweden) and included their mycelia.

it is difficult to exclude this kind of fluorescence signal from the total fluorescence.

However, as an advantage of single particle detection, a variable threshold value can be described and used. Laboratory analysis of several biological and non-biological aerosols gives an idea about fluorescence behavior of nonbiological aerosols. We present a laboratory analysis of several representative biological and non-biological particles. We will show that non-biological particles produce few false positive FBAP or saturated measurements, even under high concentrations. On the other hand, the biological particles used never saturate the fluorescence detectors. Hence, we propose a new threshold analysis that excludes particles which saturate a fluorescence channel, as well as those falling below the fluorescence baseline (Eq. 1). However, a remaining low fraction of the non-biological aerosol particles might still be misclassified. The contribution of those particles to the FBAP aerosol fraction must be quantified by laboratory studies.

\subsection{Data analysis methods}

The instrument is controlled via a laptop connected over a USB 2.0 port. Manufacturer's software is used to store the measured single particle data in comma separated value (CSV) files. The CSV files contain the particle arrival time, the forward and side scattering data, the power of the xenon lamps, the fluorescence intensities for the three different channels, the time of flight (TOF) values, the particle optical size in $\mu \mathrm{m}$ and the asymmetry factor values.

A Matlab (R2011a, Mathworks Inc.) program is used to process the single particle data and to calculate the missed particle counts. The program was written and applied for

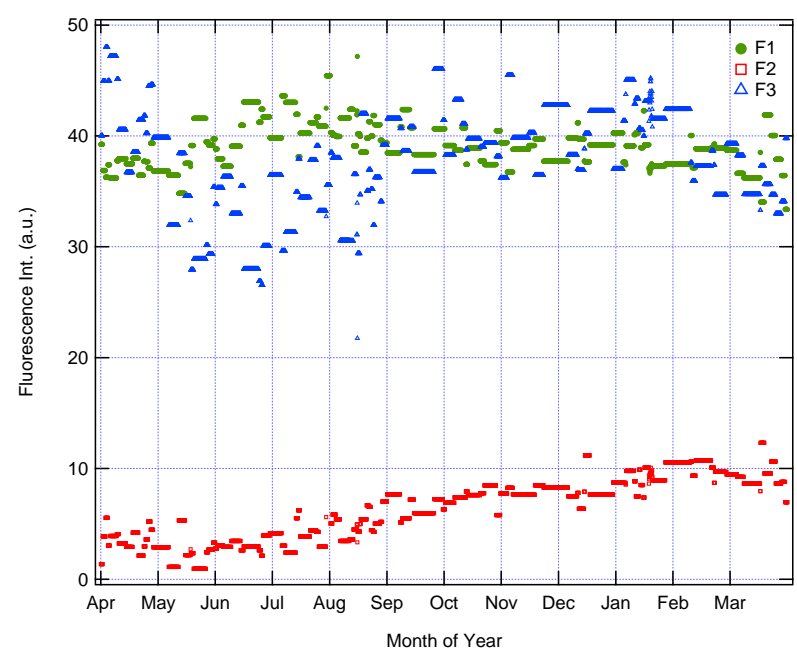

Fig. 2. Background fluorescence intensity change during a one year measurement period.

WIBS-3 data in previously published studies (Gabey et al., 2010, 2011). Because of the huge amount of single particle data, the data sets were binned into 15 min time bins and analyzed. The Matlab code searches through all data and collects the marked forced trigger data for each individual channel and calculates $\bar{E}_{i}$ and $\sigma_{i}$ values for the individual channels (cf. Sect. 2.2). According to Eq. (1), the threshold intensity is calculated ( $\left.E_{\text {Threshold }}\right)$ and all single particles having a fluorescence signal above this threshold value and not saturating any fluorescence channel are accepted as fluorescent biological aerosol particles. The missed particle count (MPC) is also calculated by the Matlab program.

\section{Results and discussion}

\subsection{Laboratory aerosol tests}

The experiments were conducted at the stainless steel aerosol chamber NAUA at the Institute for Meteorology and Climate Research in Karlsruhe, Germany (IMK-AAF, KIT). The experiments were conducted within the large international campaign BIO-05, whose focus was the role of biological aerosols in cloud formation and ice nucleation. The chamber has a volume of $3.7 \mathrm{~m}^{3}$ and is equipped with a comprehensive set of aerosol instruments. Number concentration and size distribution of the aerosol in the chamber were measured by the set of devices including the WIBS-4, an Aerodynamic Particle Sizer (APS, TSI mod. 3321) as well as a Condensation Particle Counter (CPC, TSI mod. 3022, 3775). CPC 3022 has a maximum detectable size of around $3 \mu \mathrm{m}$. The minimum particle sizes for the CPC 3022 can be given as $0.007 \mu \mathrm{m}$ (with $50 \%$ counting efficiency) and $0.015 \mu \mathrm{m}$ (with $90 \%$ counting efficiency). 
Because the WIBS-4 detection method is based on the measurement of intrinsic fluorescence from single atmospheric aerosol particles, it is likely that there are nonbiological components in the atmospheric aerosol that show a detectable amount of fluorescence signal. For instance, soot particles from combustion processes, which contain polycyclic aromatic hydrocarbon (PAH) components, contribute to the $\mathrm{PM}_{2.5}$ (fine air particle matter) mass of the atmospheric aerosol (Schauer et al., 2004). These aerosol components show fluorescence emission after excitation with UV light (Pöhlker et al., 2012). Several laboratory experiments were performed in this study to investigate the efficiency of WIBS4 for discriminating biological aerosol from non-biological aerosol. Several main atmospheric aerosol components, including ammonium sulphate, soot, and mineral dusts, were used in these experiments. Based on the results of these laboratory tests, it is possible to optimize the threshold detection levels of WIBS-4 in order to get a good discrimination of non-biological and biological aerosol particles (cf. Sect. 2.2). This optimization is a trade-off between higher threshold values, which can cause a non-detection of some biological aerosol species, and relatively low thresholds, which can cause a significant misclassification of non-biological particles.

\subsubsection{Ammonium sulphate and fungal spores}

Figure 3 shows the number and size distributions of mixture of two atmospheric aerosols, which were measured by WIBS-4 from the NAUA chamber. First, ammonium sulphate aerosol was added to the chamber until the number concentration measured by the CPC reached an initial value around $5 \times 10^{4} \mathrm{~L}^{-1}$. The ammonium sulphate aerosol had been sampled for approximately $80 \mathrm{~min}$ before about $2 \times 10^{4} \mathrm{~L}^{-1}$ of penicillium notatum type of spores were added. At that time the CPC number concentration of the ammonium sulphate particles had already dropped to about $2.5 \times 10^{4} \mathrm{~L}^{-1}$. The time evolution of the experiment is illustrated in Fig. 3. Because of the different size ranges of the CPC and WIBS-4 instruments, the total number concentration measured by WIBS-4 for the ammonium sulphate aerosol and ammonium sulphate-fungal spore mixture were around $0.6 \times 10^{4} \mathrm{~L}^{-1}$ and $1.0 \times 10^{4} \mathrm{~L}^{-1}$, respectively.

The average $N_{\mathrm{F} 1, \mathrm{~F} 3}$ number concentrations deduced from the WIBS-4 fluorescence data for ammonium sulphate aerosol and ammonium sulphate-fungal spore mixture were around $1.0 \mathrm{~L}^{-1}$ and $0.2 \times 10^{4} \mathrm{~L}^{-1}$, respectively. The $N_{\mathrm{F} 1, \mathrm{~F} 3} N_{\mathrm{T}}^{-1}$ ratio was less than $0.01 \%$ for the pure ammonium sulphate aerosol and around $20 \%$ for the ammonium sulphate-fungal spore mixture. If WIBS-4 had classified all of the fungal spores $\left(\sim 0.4 \times 10^{4} \mathrm{~L}^{-1}\right)$ in the chamber as biological, the $N_{\mathrm{F} 1, \mathrm{~F} 3} N_{\mathrm{T}}^{-1}$ ratio would be around $40 \%$. But the $N_{\mathrm{F} 1} N_{\mathrm{T}}^{-1}$ ratio was less than $1 \%$ for the pure ammonium sulphate aerosol and around $35 \%$ for ammonium sulphate-fungal spore mixture (which is close to a $100 \%$ detection efficiency). The most likely reason for this difference is a lower sensitivity of channel F3 compared to channel F1. However, it is also conceivable that a fraction of fungal spores exhibit weaker NADH-like signal and cannot exceed our notably high background threshold. Figures $3 \mathrm{a}$, b are represented side by side to compare the $N_{\mathrm{F} 1}$ and $N_{\mathrm{F} 1, \mathrm{~F} 3}$ ratios. By comparing panels (a) and (b) of Fig. 3, it can be seen that the combination of $\mathrm{F} 1$ and $\mathrm{F} 3$ channels (ref. Table 1) results in a much better discrimination of the biological particles. Figure 3a shows that the ammonium sulphate aerosol fluoresces weakly in channel $\mathrm{F} 1$, which is the short wavelength excitation and detection. On the other hand, using a combination of the two fluorescence detection channels F1 and F3 suppresses almost all ammonium sulphate aerosol particles in the fluorescence measurements in the case of penicillium notatum/ammonium sulphate mixture (Fig. 3b).

\subsubsection{Mineral dust}

Mineral dust is also one of the most abundant aerosols in the atmosphere (Rosenfeld et al., 2008; Monks et al., 2009) and its fluorescence ability might be the strongest interference factor of the UV-LIF method. To investigate the fluorescence behavior of mineral dust, a series of experiments with mineral dust aerosol were performed during BIO-05. Because of its atmospheric relevance, a Saharan dust sample was used. The Saharan dust (SD2) is a surface sample that was collected about $50 \mathrm{~km}$ north of Cairo, Egypt. Elemental composition of the dust sample and some other details can be found elsewhere (Möhler et al., 2006). A small-scale powder disperser (SSPD 3433, TSI) was used for dispersing the Saharan dust into the NAUA chamber. The initial CPC number concentration after the addition of the dust was about $55 \mathrm{~cm}^{-3}$. The Saharan dust sample used in the chamber had a size distribution between 0.05-2.5 $\mu \mathrm{m}$ (Möhler et al., 2006). Because of the fact that the WIBS-4 can measure the optical particle size for only particles greater than $0.5 \mu \mathrm{m}$, we observed a lower total aerosol number concentration compared to the CPC measurement. Therefore, Fig. 4 represents only the particles corresponding to an optical size between 0.8 and $16 \mu \mathrm{m}$. The total aerosol number concentration $N_{\mathrm{T}}$ was measured to be between $2 \times 10^{3}$ and $6 \times 10^{3} \mathrm{~L}^{-1}$.

We did the same analysis as in the ammonium sulphate case and compared the number concentrations of Saharan dust aerosols for different definitions of biological aerosol. Figure 4a shows the number of fluorescent particles using channel F1, while Fig. $4 \mathrm{~b}$ represents the combination of F1 and F3 channels. Number concentrations of Saharan dust aerosol by using channel $\mathrm{F} 1$ were found to be between $10^{2}$ to $10^{3} \mathrm{~L}^{-1}$, while the $N_{\mathrm{F} 1, \mathrm{~F} 3}$ varied between $10^{1}$ to $10^{2} \mathrm{~L}^{-1}$. Although it was not possible to suppress all Saharan dust particles, as in the case of ammonium sulphate aerosol, using the combination of F1 and F3 for discrimination of biological aerosol resulted in a lower contribution from Saharan dust particles. The fluorescent to total aerosol number 

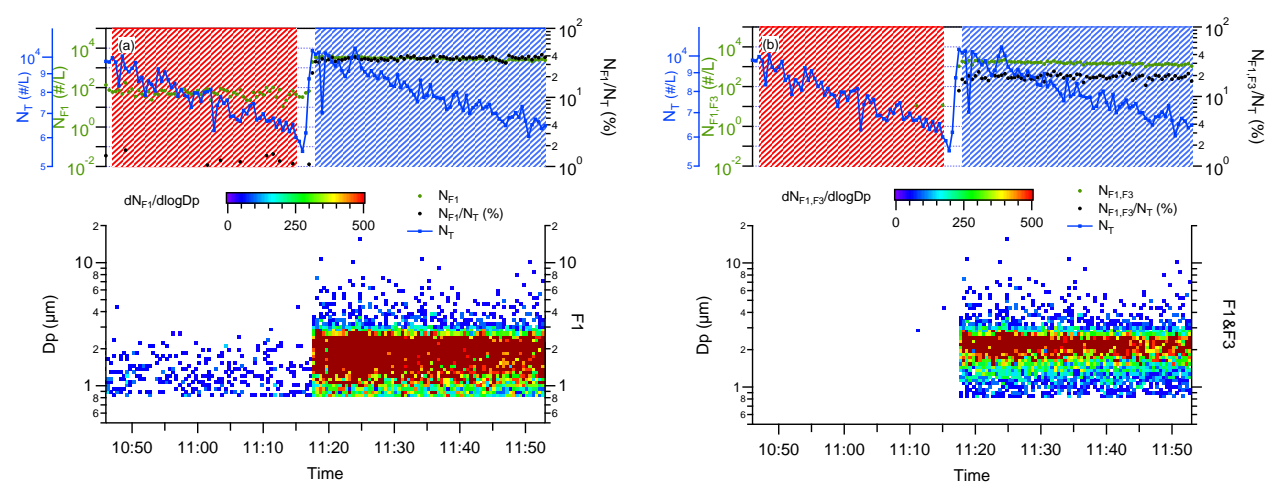

Fig. 3. WIBS-4 fluorescence data for ammonium sulphate aerosol and penicillium notatum spores measured during the BIO-05 campaign (24 March 2010 at IMK-AAF, KIT). Upper panel, left axis: number concentrations of all detected particles and fluorescent biological aerosol particles in the size range $0.8-16 \mu \mathrm{m}$, blue and green markers, respectively. Upper panel, right axis: ratio of the number of fluorescent particles to the total number concentration, black markers. Lower panel: Size distribution $\left(\mathrm{d} N / \mathrm{d} \log D_{\mathrm{p}}\right)$ of fluorescent particles for the entire experiment period. The experimental period of pure ammonium sulphate aerosol is highlighted by a red shaded area, while the mixture of ammonium sulphate and fungal spores is represented by a blue shaded area. Panel (a) shows the results using only events in channel F1 for discriminating biological particles, while (b) uses the combination of simultaneous events in channels F1 and F3.
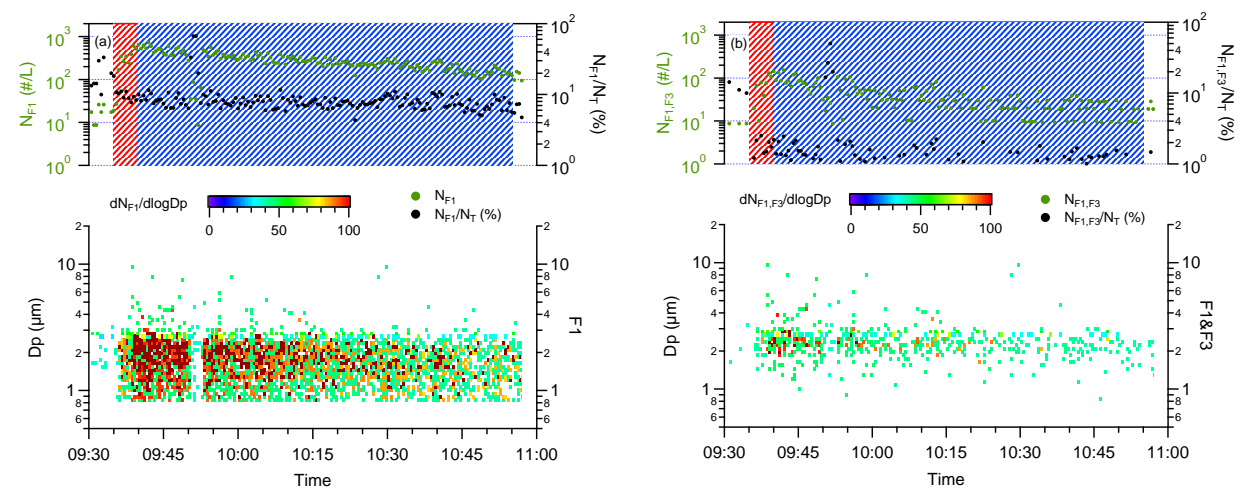

Fig. 4. WIBS-4 fluorescence data for a Saharan dust aerosol experiment conducted during BIO-05. The data are plotted in the same way as in Fig. 3. Red shaded area indicates the addition of Saharan dust aerosol into the chamber, while blue shaded area indicates the integrated sampling time.

concentration ratio $\left(N_{\mathrm{F} 1} N_{\mathrm{T}}^{-1}\right)$ was around $10 \%$ when using the F1 channel, while $N_{\mathrm{F} 1, \mathrm{~F} 3} N_{\mathrm{T}}^{-1}$ was only around $1 \%$. If we assume an extreme case of an ambient dust aerosol number concentration of 600 particles $\mathrm{L}^{-1}$, which corresponds to a typical total aerosol concentration at our sampling site (Table 2), the mineral dust aerosol would contribute by less than 6 particles $\mathrm{L}^{-1}$ to the biological aerosol number concentration. If we assume that Saharan dust aerosol exhibits strong tryptophan-like and NADH-like peaks (like the sample used in our study), WIBS-4 may misclassify a significant amount of non-biological aerosol as biological. However, new laboratory studies show that mineral dust aerosol fluoresces weakly in both F1 and F3 detection ranges and their fluorescence intensity is considerably weaker compared with the biofluorophores (Pöhlker, 2012; Toprak et al., unpublished study). We report here the maximum cross-sensitivity of F1 and F3 to non-biological aerosol. Therefore, presented $N_{\mathrm{F} 1, \mathrm{~F} 3}$ numbers may be lower than they in fact could be.

Nevertheless, the nature of the observed fluorescence behavior of Saharan dust is quite interesting. Recent studies show that biological substances attached to dust particles can travel over long distances and, therefore, strong sand storms might disperse viable microbes over wide continental regions (Hallar et al., 2011) or even globally (Smith et al., 2011). In this context we can speculate that Fig. $4 \mathrm{~b}$ can be either the result of a misclassification in which mineral dust particles produce false positives, or could be the first indication of microorganisms on the dust particles, which can produce true signals. In our case, it was not possible to clarify this behavior by using the available measurements. However, this will be the subject of forthcoming studies. 


\subsubsection{Soot aerosol}

Soot aerosol is emitted through combustion processes, contributes to atmospheric aerosol and its major sources are fossil fuel and biomass burning (Cooke et al., 1999). Basically, soot consists of black carbon and other combustiongenerated carbonaceous materials. Past studies report that soot aerosol contains fluorescent polycyclic aromatic hydrocarbons (PAH), and therefore might be a significant interference factor for the UV-LIF method in detecting biological particles (Schauer et al., 2004; Gabey et al., 2011; Pöhlker et al., 2012). We used aerosol emissions from a propane diffusion flame (mini-CAST, Jing Ltd, Switzerland) to investigate the WIBS-4 fluorescence detection behavior in cases of fossil fuel combustion aerosol. The CAST burner can be operated under different fuel-to-oxygen $(\mathrm{C} / \mathrm{O})$ ratios in order to generate soot aerosol emissions with different organic carbon contents (Schnaiter et al., 2006). During the BIO-05 campaign, we used CAST combustion aerosol that was generated at a $\mathrm{C} / \mathrm{O}$ ratio of 0.5 . The soot aerosol was mixed with ammonium sulphate aerosol in the NAUA aerosol chamber. The initial CPC aerosol number concentration of the mixture was around $1.7 \times 10^{5} \mathrm{~L}^{-1}$, which dropped to around $1.0 \times 10^{5} \mathrm{~L}^{-1}$ over the course of the experiment mainly due to dilution. The total aerosol number concentration of the particles with optical diameters larger than $0.8 \mu \mathrm{m}$, as measured by the WIBS-4 instrument, was around $5.0 \times 10^{3} \mathrm{~L}^{-1}$.

The time evolution of the experiment is again illustrated in the same way as the previous experiments (Fig. 5). By using the combination of F1 and F3 fluorescent channels, the $N_{\mathrm{F} 1, \mathrm{~F} 3}$ was found around $10 \mathrm{~L}^{-1}$ for ammonium sulphate and soot aerosol mixture. $N_{\mathrm{F} 1} N_{\mathrm{T}}^{-1}$ and $N_{\mathrm{F} 1, \mathrm{~F} 3} N_{\mathrm{T}}^{-1}$ were found around $1.21 \%$ and $0.17 \%$, respectively. When we compare Figs. 5a and b, we see that the combination of F1 and F3 provides a much better discrimination of non-biological aerosol. However, there is a remaining interference of about $0.2 \%$ from non-biological aerosol. According to our first experiment, which quantifies the fluorescence signal coming from ammonium sulphate aerosol, it can be accepted that all measured fluorescence is due to the soot aerosol. If we assume total aerosol number concentrations expected in a semirural area to be around $600 \mathrm{~L}^{-1}$ (see the results presented in Sect. 3.2), combustion aerosol emissions might contribute to the detected fluorescent biological aerosol number concentration by about one particle $\mathrm{L}^{-1}$ at most.

\subsubsection{Bacteria}

After testing several non-biological and biological aerosol mixtures, we had the opportunity to make some test measurements by using different bacterial species, which were prepared within the BIO-05 campaign for the purpose of investigating their ice nucleation capabilities in cloud chamber experiments. We present here only one example from the cloud expansion experiments that were done within the
BIO-05 campaign. The following results clearly show the capability of WIBS-4 in the detection of bacterial species. Because we did not use classical bacterial growing methods to check the viability status of the used bacterial strains, we can only speculate about the viable and non-viable bacteria number concentration during these experiments. Assuming that channel F1 measures only the fluorescence from tryptophan (which is an indicator for biological organisms) and that channel F3 from NADH (which is an indicator for living biological organisms), we can speculate that the combination of F1 and F3 gives the fraction of viable species. The lower plots in Figs. 6a and Fig. 6b show that (i) all bacterial cells in the cloud chamber (AIDA) were counted based on the F1 channel, and (ii) only a minor fraction of those particles were classified to be alive based on the F1\&F3 combination. This would mean that only around $10 \%$ of all bacterial cells managed to survive the harsh conditions in the AIDA cloud chamber. Although this interpretation is quite speculative at the moment, the observation gives us the motivation for future studies. These studies will aim at the comparison of WIBS4-based bacteria detection capabilities with classical techniques in order to see if the instrument can also reliably discriminate the fraction of viable bacterial cells.

To summarize conclusions from the above laboratory experiments, we can say that the fluorescence signal from ammonium sulphate aerosol can be completely suppressed by using the combination of the F1 and F3 fluorescence channels. The second important result of these experiments is that we showed that there was a small but significant amount of fluorescence signal induced by mineral dust particles. This could be either the first indicator of biological species residing on the surfaces of the dust particles or a limitation of the technique, which may be overcome by altering the fluorescence threshold. Another important finding is the low cross sensitivity of the used biological aerosol definition (F1 and F3) to CAST fossil fuel combustion aerosol, which was found to be only around $0.2 \%$.

\subsection{Ambient measurements}

We used the WIBS-4 to characterize the ambient aerosol in the vicinity of the IMK-AAF (Institute for Meteorology and Climate Research, Atmospheric Aerosol Research) building at KIT (Karlsruhe Institute of Technology, Campus North) in Karlsruhe, Germany $\left(49^{\circ} 5^{\prime} 43.58^{\prime \prime} \mathrm{N}, 8^{\circ} 25^{\prime} 45.048^{\prime \prime} \mathrm{E} ; 112\right.$ $\mathrm{m}$ a.s.l.). The WIBS-4 inlet was placed on the roof of the aerosol laboratory, i.e. approximately $5 \mathrm{~m}$ above the ground. We used a total duspended particles inlet (TSP, Digitel, Model DTSP01/00/16) to sample ambient aerosol. The TSP inlet is an omnidirectional inlet, which is widely used for general particulate pollution monitoring. There are different versions available for both high volume and low volume air pollution monitoring applications. In our study, we used the low-volume TSP inlet that requires a sample flow rate of $1 \mathrm{~m}^{3} \mathrm{~h}^{-1}\left(16.67 \mathrm{~L} \mathrm{~min}^{-1}\right)$. With this sample flow rate 

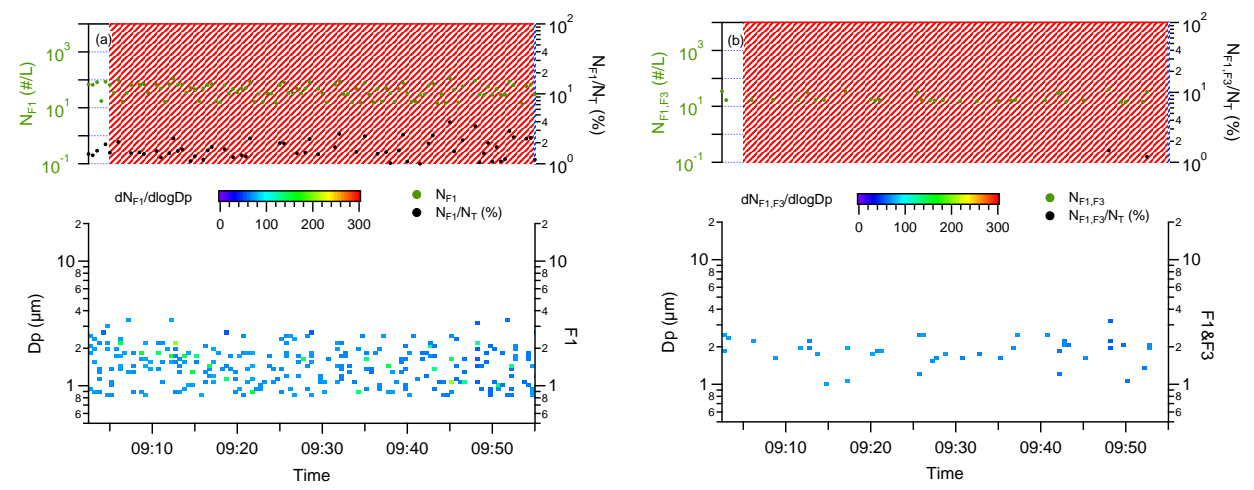

Fig. 5. WIBS-4 fluorescence data for ammonium sulphate-CAST soot aerosol mixture experiment conducted during BIO-05. The data are plotted in the same way as in Fig. 3. Pre-experimental period illustrated by a colorless area, while ammonium sulphate-CAST soot aerosol mixture is represented by a red shaded area.
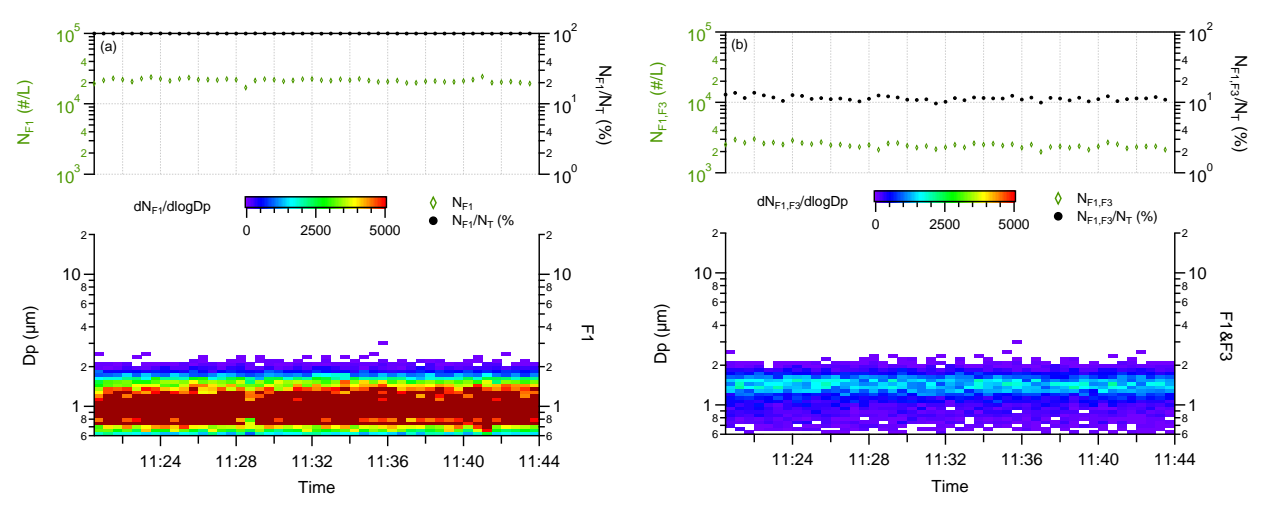

Fig. 6. WIBS-4 fluorescence data for Pseudomonas syringae type of bacterium isolated from cloud water. Fluorescence data were collected during a cloud experiment conducted during BIO-05 campaign. Average residence time of the bacterial species in the chamber was approximately $1 \mathrm{~h}$. The physical size of the bacterial strains was around $1.0 \mu \mathrm{m}$. The data are plotted in the same way as in Fig. 3 .

the TSP inlet is specified to collect particles with a wide spectrum of sizes up to around $30-40 \mu \mathrm{m}$. The $13 \mathrm{~mm}$ inner diameter stainless steel sampling tube downstream the TSP inlet penetrates the roof of the laboratory where it is fitted to a $40 \mathrm{~mm}$ inner diameter flow tube, which is operated at flow rate of $16.67 \mathrm{~L} \mathrm{~min}^{-1}$. At the far end of this tube another $13 \mathrm{~mm}$ inner diameter sampling tube penetrates the wider flow tube by about $40 \mathrm{~cm}$, forming an isokinetic sampling tube for WIBS-4, which has a sample flow rate of $2.5 \mathrm{~L} \mathrm{~min}^{-1}$. The sampling is said to be isokinetic when it is isoaxial and the mean sample flow velocity through the face of the inlet is equal to the gas flow velocity (Baron et al., 2001). The final connection between WIBS-4 and the TSP isokinetic inlet system was made using an electrically conductive silicon rubber tube (length $35 \mathrm{~cm}$, inner diameter $13 \mathrm{~mm}$ ). The overall length of the sampling line is about $3 \mathrm{~m}$. Note that the sampling system is strictly vertical, i.e. there are no horizontal sampling sections, which avoids sedimentation losses.
The measurement site is surrounded by a forest from the north-east to the south-west and has a distance from the closest highway of almost $550 \mathrm{~m}$. Ambient temperature $(T)$, relative humidity (RH) and pressure were simultaneously measured using a chilled mirror hygrometer. Wind speed and direction were measured by using a 3-D sonic anemometer (USA-1, $\mathrm{ACH}+T$, one second time resolution). We obtained additional wind data together with precipitation $(\mathrm{mm})$ and global solar radiation $\left(\mathrm{W} \mathrm{m}^{-2}\right)$ data from the meteorological tower of KIT located about $500 \mathrm{~m}$ to the south-west of the measurement site. WIBS-4 sampled the ambient air continuously over a period of $1 \mathrm{yr}$ (1 April 2010-1 April 2011). The measurement stopped sometimes because of undefined problems with the data acquisition software. Those missing data periods are represented by gaps in the figures below.

As a consequence of the findings from the above laboratory tests, we used the combination of the two fluorescence channels F1 and F3, which will be called FBAP after this point, to discriminate biological from non-biological aerosol particles in the ambient atmosphere. Since several studies 

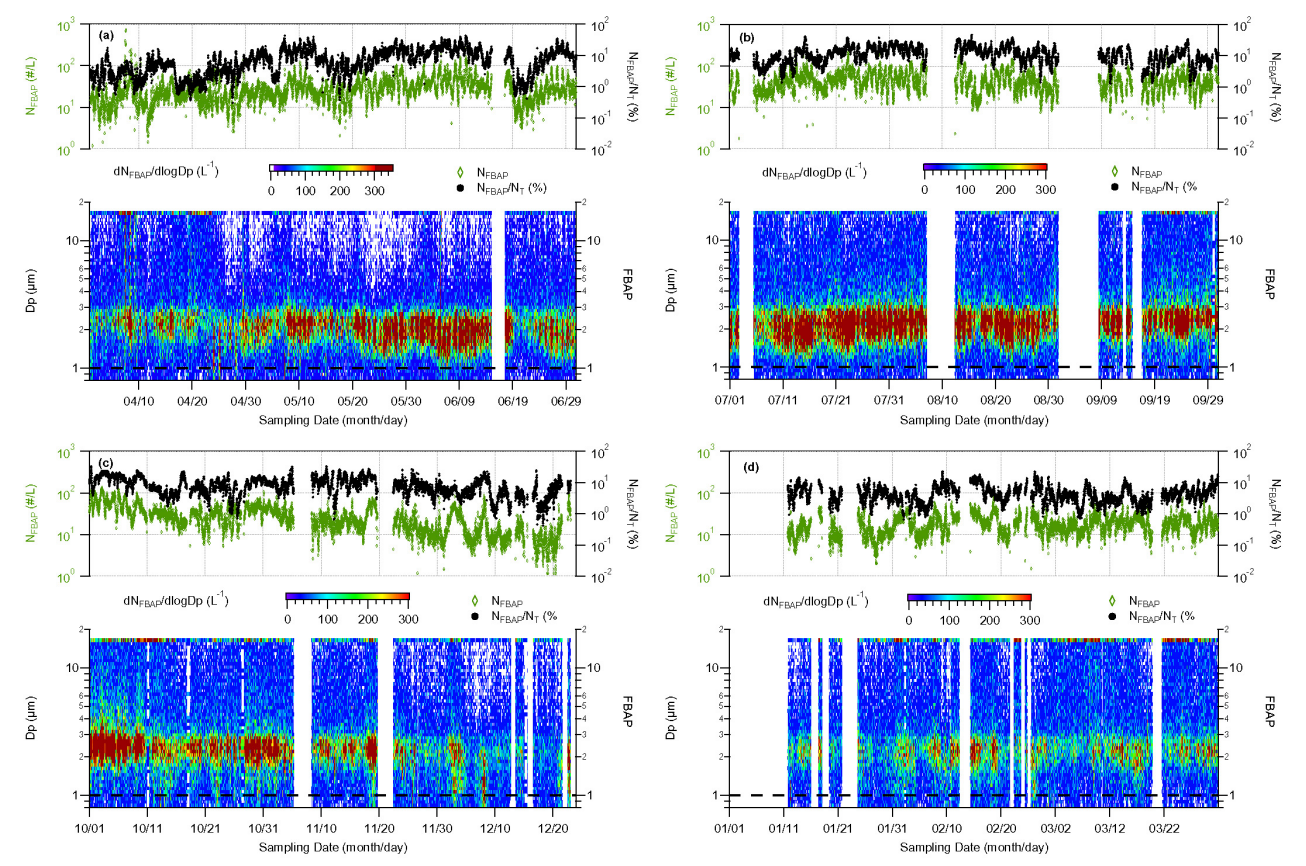

Fig. 7. WIBS-4 fluorescence data for one year online measurement term (April 2010-March 2011). The data are plotted in the same way as in Fig. 3. The color scale in the lower image plots represents $\mathrm{d} N_{\mathrm{FBAP}} / \mathrm{d} \log D_{\mathrm{p}}$. (a) spring, (b) summer, (c) autumn, and (d) winter period.

have revealed that most likely FBAP candidates exhibit both tryptophan-like and NADH-like peaks, in this study we used the acronym "FBAP" following the definition by Gabey et al. (2010). First of all, the reader should keep in mind that Gabey et al. used WIBS-3 rather than WIBS-4 and there are small differences in emission bands of two instruments. Secondly, the definition of FBAP by Huffman et al. (2010) relies only on NADH-like peaks (excitation at $355 \mathrm{~nm}$, detection $420-575 \mathrm{~nm}$ ), while Gabey et al. (2010) used both tryptophan-like and NADH-like peaks. We would like to draw attention in the case of any direct comparison between different studies using the same acronym "FBAP" to define biological aerosols. Moreover, Gabey (2011) reported that channel F1 is more sensitive to bacterial species whilst F3 is more sensitive to plant spores. They also conclude that the combination of $\mathrm{F} 1$ and $\mathrm{F} 3$ provides more information about fungal spores. Fifteen-minute averages of the FBAP number concentrations, the relative FBAP aerosol fractions and their size distributions are illustrated in Fig. 7. To highlight the seasonal variability of the atmospheric FBAP component, Fig. 7 is composed of 4 panels representing the spring (April-June), summer (July-September), autumn (OctoberDecember) and winter (January-March) periods.

Based on this one-year data set, we can conclude that $N_{\text {FBAP }}$ and $N_{\mathrm{T}}$ showed large variability (see Fig. 8 and Table 2). However, the FBAP number concentrations and number fractions exhibit a clear seasonal cycle. We observed high FBAP number concentrations and FBAP number fractions from late spring until early autumn. On the other hand,
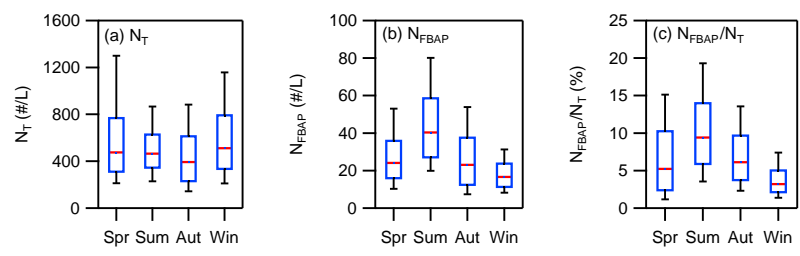

Fig. 8. Statistical representation of FBAP number concentrations and $N_{\mathrm{FBAP}} / N_{\mathrm{T}}$ for different seasons as box-and-whisker plots. Red solid line represents median (50th percentile), lower and upper limits of blue box show 25th and 75th percentiles, respectively. The black error bars show 10th and 90th percentiles.

we found lowest FBAP number concentrations in the winter period. These results are also in good agreement with the typical fungal spore releases in Europe (Winiwarter et al., 2009). In spring, $N_{\mathrm{FBAP}}$ changed between $1.2-337 \mathrm{~L}^{-1}$ while the relative contribution of FBAP to the total aerosol particle (TAP) varied between $0.26-40 \%$ (Fig. 7a). In summer, $N_{\text {FBAP }}$ and $N_{\text {FBAP }} N_{\mathrm{T}}^{-1}$ were between $0.58-244 \mathrm{~L}^{-1}$ and between $0.90-42 \%$, respectively (Fig. $7 \mathrm{~b}$ ). In autumn, $N_{\text {FBAP }}$ and $N_{\mathrm{FBAP}} N_{\mathrm{T}}^{-1}$ varied between $0.29-135 \mathrm{~L}^{-1}$ and between $0.32-0 \%$, respectively (Fig. 7c). The ranges of FBAP number concentrations and $N_{\mathrm{FBAP}} N_{\mathrm{T}}^{-1}$ aerosol fractions were significantly reduced in the winter period to ranges of 0.29 $80 \mathrm{~L}^{-1}$ and $0.43-18 \%$, respectively (Fig.7d).

Figure 8 shows the statistical analysis of the fifteen-minute average number concentrations for the individual seasons. 
Table 2. Integrated number concentrations for different measurement periods in the case of $N_{\mathrm{T}} \& N_{\mathrm{FBAP}}(0.8-16 \mu \mathrm{m})$ : monthly and annual mean and median values between 1 April 2010 and 1 April 2011.

\begin{tabular}{lllllll}
\hline Quantity & & Apr-Jun & Jul-Sep & Oct-Dec & Jan-Mar & One-year \\
\hline$N_{\mathrm{T}}\left(\mathrm{L}^{-1}\right)$ & 25 th & 310 & 347 & 230 & 335 & 305 \\
& Mean & 691 & 520 & 468 & 633 & 583 \\
& Median & 474 & 465 & 392 & 510 & 461 \\
& 75 th & 770 & 629 & 612 & 790 & 690 \\
\hline$N_{\text {FBAP }}\left(\mathrm{L}^{-1}\right)$ & 25th & 16 & 27 & 13 & 11 & 15 \\
& Mean & 29 & 46 & 29 & 19 & 31 \\
& Median & 24 & 40 & 23 & 17 & 25 \\
& 75 th & 36 & 59 & 38 & 24 & 39 \\
\hline \multirow{2}{*}{$N_{\text {NON }}\left(\mathrm{L}^{-1}\right)$} & 25th & 195 & 188 & 145 & 228 & 188 \\
& Mean & 545 & 354 & 310 & 426 & 416 \\
& Median & 338 & 287 & 234 & 354 & 300 \\
& 75 th & 625 & 468 & 435 & 595 & 530 \\
\hline$N_{\text {FBAP }} / N_{\mathrm{T}}(\%)$ & 25th & 2.2 & 6 & 3.7 & 2 & 3.1 \\
& Mean & 7.02 & 10.6 & 7.15 & 3.87 & 7.34 \\
& Median & 5.22 & 9.4 & 6.11 & 3.20 & 5.76 \\
& 75 th & 11 & 14 & 9.5 & 5 & 10.1 \\
\hline
\end{tabular}

The corresponding values are also tabulated in Table 2. As already mentioned, the statistical analysis of the data revealed that fluorescent biological aerosol number concentrations $\left(N_{\mathrm{FBAP}}\right)$ and the relative contribution of FBAP to TAP $\left(N_{\text {FBAP }} N_{\mathrm{T}}^{-1}\right)$ exhibited a clear seasonal dependence (Fig. $8 \mathrm{~b}$ and c). On the other hand, the seasonal mean of $N_{\mathrm{T}}$ (Fig. 8a) was almost constant over the course of our one-year sampling period, which had the minimum value in autumn and the maximum value in spring. In contrast to the summer and autumn periods, the spring and winter $N_{\mathrm{T}}$ possessed strong fluctuations, which are reflected in the length of the corresponding 10-90th percentile bars in Fig. 8a. We can speculate that these fluctuations are due to local sources (e.g. grass cutting events around the site). These fluctuations appeared also in the figures which show the diurnal change of $N_{\mathrm{T}}$ (Fig. 10).

We also analyzed the diurnal changes in the FBAP and TAP number concentrations and distributions. Figure 9 represents these diurnal changes of FBAP for the different seasons. In the spring term, $N_{\text {FBAP }}$ started to increase after sunset and reached its maximum value in the early morning hours (Fig. 9a). The lowest $N_{\text {FBAP values were measured dur- }}$ ing daytime, between 12:00 and 15:00. On the other hand, we observed a steep increase in $N_{\mathrm{T}}$ after sunrise and the maximum TAP number concentrations were observed during daytime (Fig. 10a). After 15:00, $N_{\mathrm{T}}$ started to decrease until sunset. After sunset, $N_{\mathrm{T}}$ slightly increased and stayed constant until the next sunrise. We observed also oberved a diel mode at $\sim 2.5 \mu \mathrm{m}$ for FBAP. In summer, we again observed clear diurnal changes in FBAP and TAP number concentrations. $N_{\text {FBAP }}$ was, like in spring term, high between 18:00 and 09:00 (Fig. 9b). In addition, the decrease in the $N_{\text {FBAP }}$ shifted to early noon hours. Similar to the spring, $N_{\mathrm{T}}$ was high during daytime and lower but almost constant between 17:00 and 06:00. A steep increase in $N_{\mathrm{T}}$ was again observed after sunrise until 12:00 and it started to decrease again after 12:00. We observed the same diel mode at $\sim 2.5 \mu \mathrm{m}$ which suggests the release of a specific type of biological aerosol around the measurement site. The observed diurnal changes in TAP number concentrations with larger concentrations of bigger particles during daytime suggest that the reported diurnal changes of the $N_{\text {FBAP }}$ concentrations are not simply due to convective mixing and dilution during daytime (Garland et al., 2008, 2009), but rather a specific release mechanism. This specific release mechanism is discussed in the next section in detail.

In the autumn period, we observed a similar diurnal change of FBAP which was similar to that of the spring term (Fig. 9c). The same diel mode around $2.5 \mu \mathrm{m}$ was again observed. On the other hand, $N_{\mathrm{T}}$ stayed constant during the whole day. However, in contrast to the spring term, autumn and summer biological aerosol size showed a broader distribution. A higher number concentration of larger particles was observed, which may reflect another type of aerosol release in this time period, i.e. a different kind of fungal spore or pollen release. Since this type of aerosol consists of larger particles (here $>16 \mu \mathrm{m}$ ), they saturate the detector and fall to the last size bin of the WIBS-4 (greenish solid line on lower panels of Fig. 9b-d). Unlike the other three seasons, in winter we observed almost constant number concentrations of FBAP and TAP (Figs. 9d and 10d). Nighttime $N_{\mathrm{T}}$ values, however, were for the first time higher than during daytime. $N_{\mathrm{T}}$ started to increase after 17:00, reached its maximum value at 23:00 and started to decrease after 04:00. 

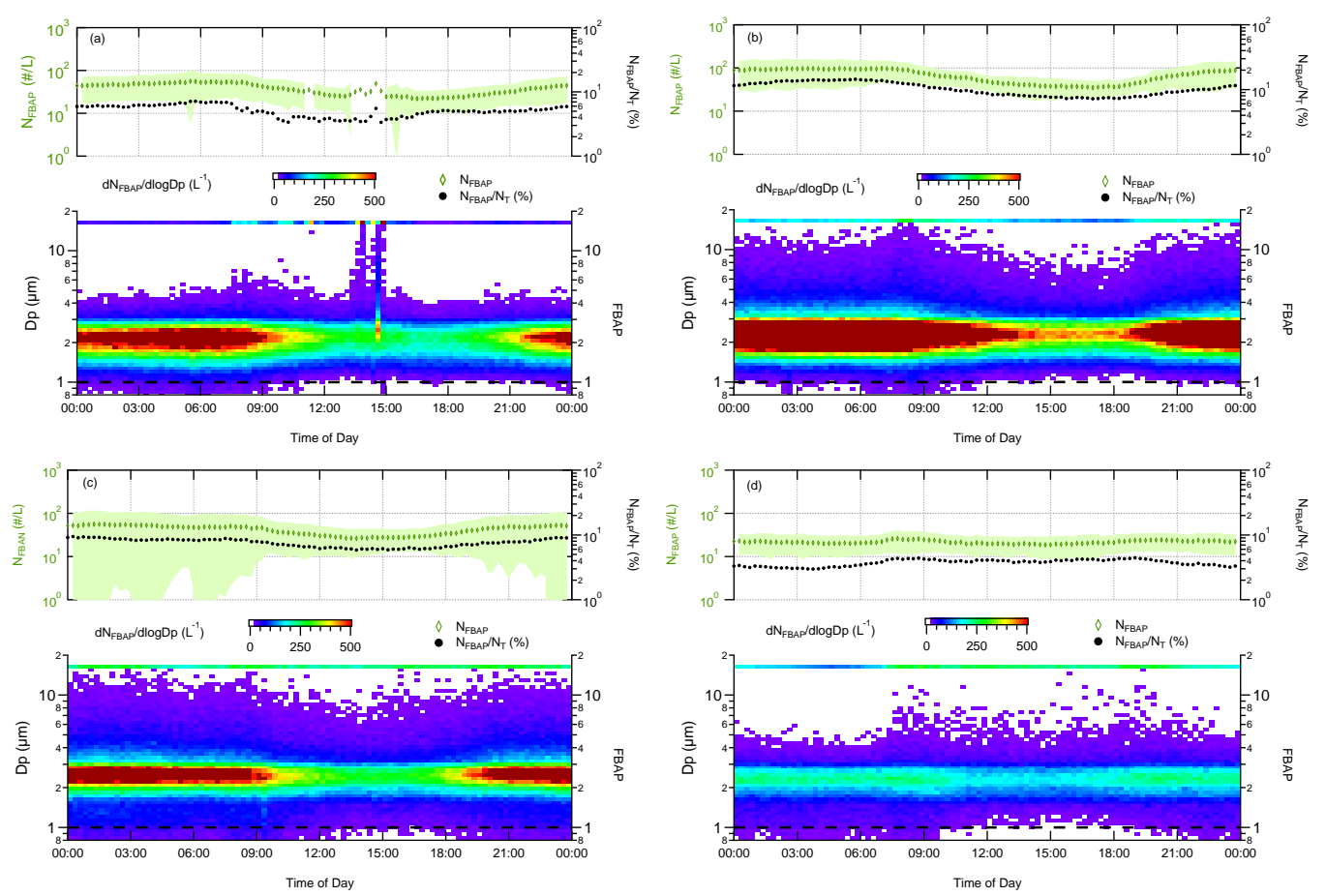

Fig. 9. WIBS-4 fluorescence data to show the diurnal changes of FBAP number concentrations and distribution for different sampling terms. The data were plotted in the same way as in Fig. 3: (a) spring, (b) summer, (c) autumn, (d) winter. The spikes on (a) around 15:00 p.m. are most probably due to some reconstruction events at and around the sampling site.
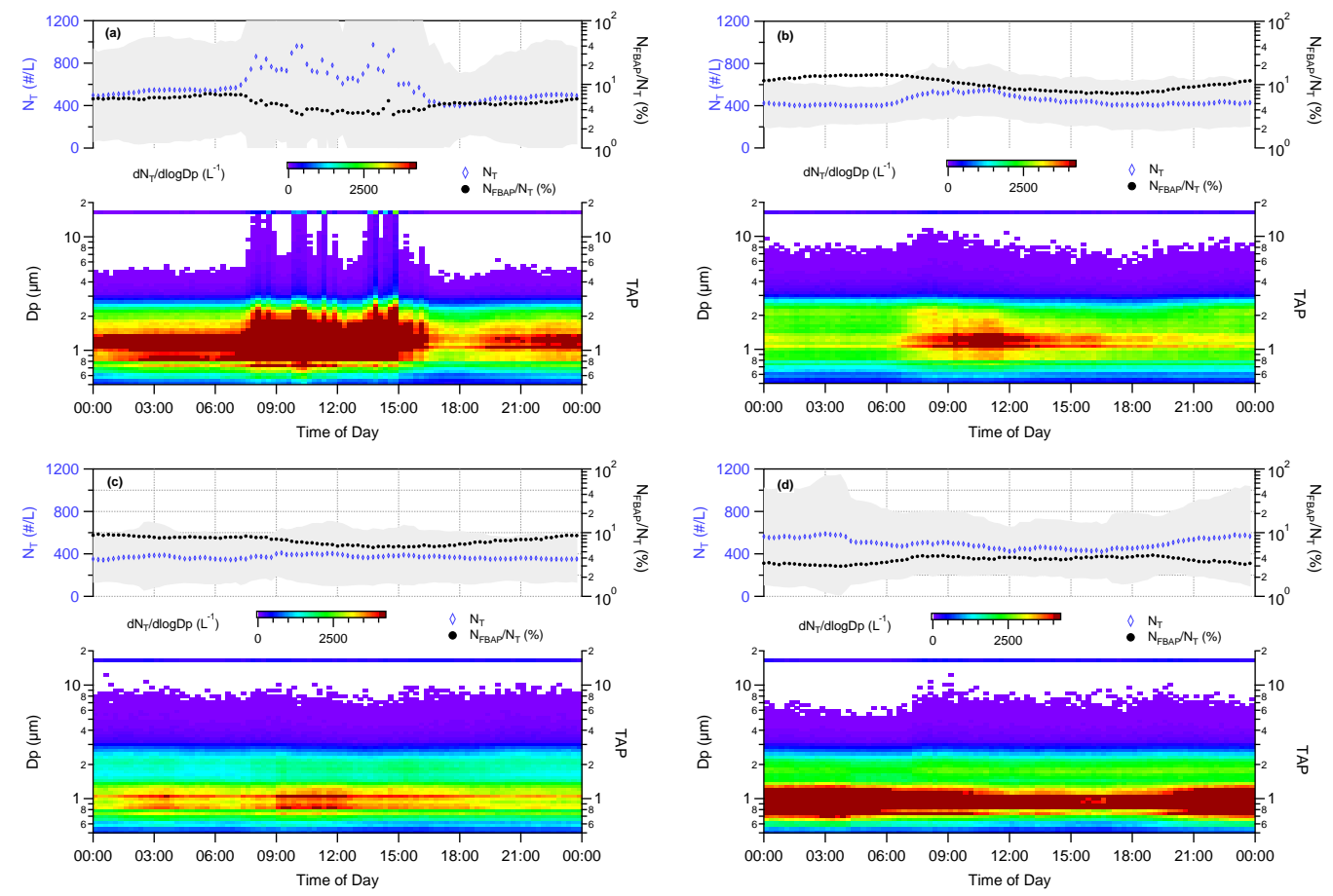

Fig. 10. Diurnal change of TAP number concentrations (upper panel) and size distributions (lower panel) for each measurement period (plots analogous to Fig. 9): (a) spring, (b) summer, (c) autumn, and (d) winter. Light-gray shaded area shows TAP concentration variability as the area between 25 th-75th percentile traces. 


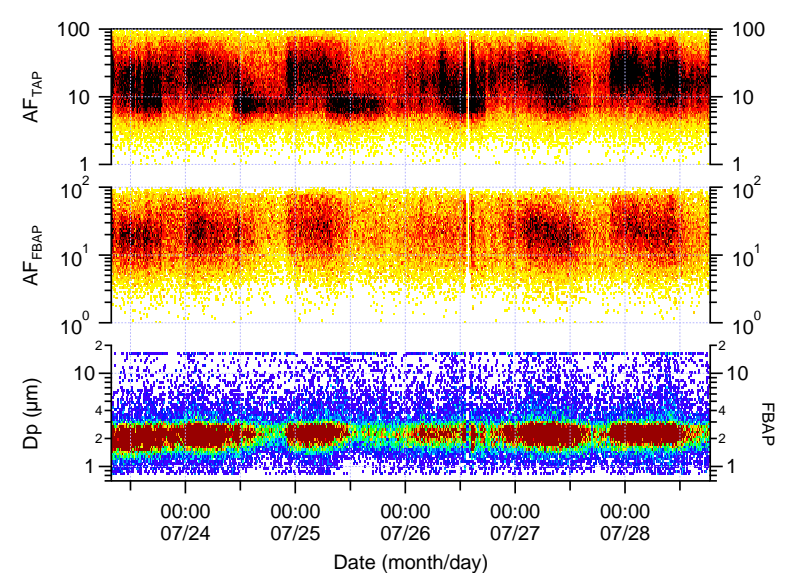

Fig. 11. Asymmetry factor (AF) data combined with fluorescence data for one selected time period in summer.

Again a diel mode of FBAP at $2.5 \mu \mathrm{m}$ was observed. However, this mode was not as clear as it was in the other three seasons.

Figure 11 shows the fluorescence data combined with asymmetry factor data for FBAP and TAP. It can be clearly seen that the observed FBAP diel mode consists of less spherical particles having AF values between 10 and 40, while TAP includes another type of aerosol which is more spherical (AF smaller than 10).

As a result of this diurnal analysis, we can give the following conclusions. First, we observed one distinct mode for FBAP at $\sim 2.5 \mu \mathrm{m}$ and with a specific particle shape, which indicates the emission of a site-specific biological aerosol type (most likely spores). Second, the diurnal change in $N_{\mathrm{T}}$ with strong fluctuations during daytime may be explained by the boundary layer mixing effects and local sources. Diurnal changes of TAP in the spring period suggest that local events can significantly influence the coarse mode $\left(D_{\mathrm{p}}>2.5 \mu \mathrm{m}\right.$, optical size) aerosol distribution and should be carefully considered to prevent any over estimation of biological and nonbiological aerosol. However, the diurnal changes of FBAPs were considerably different from the change in $N_{\mathrm{T}}$ which suggests that FBAP sources appear to have a specific release mechanism with a strong diurnal cycle.

\subsubsection{Correlation of FBAP with meteorological data}

Figures 12, 13, 14 and 15 show the fluorescence data combined with several meteorological data for four selected sampling periods. Because the fluorescence data showed certain diurnal patterns, we looked for correlations of the FBAP number concentration with different meteorological parameters. To get a first overview of the role of each meteorological parameter for this correlation, we plotted all data in the same figure. In Fig. 12 and Fig. 13, the strong correlation between $N_{\text {FBAP }}$ and the relative humidity is notable, especially during clear sky periods (indicated by distinct diurnal trends of the

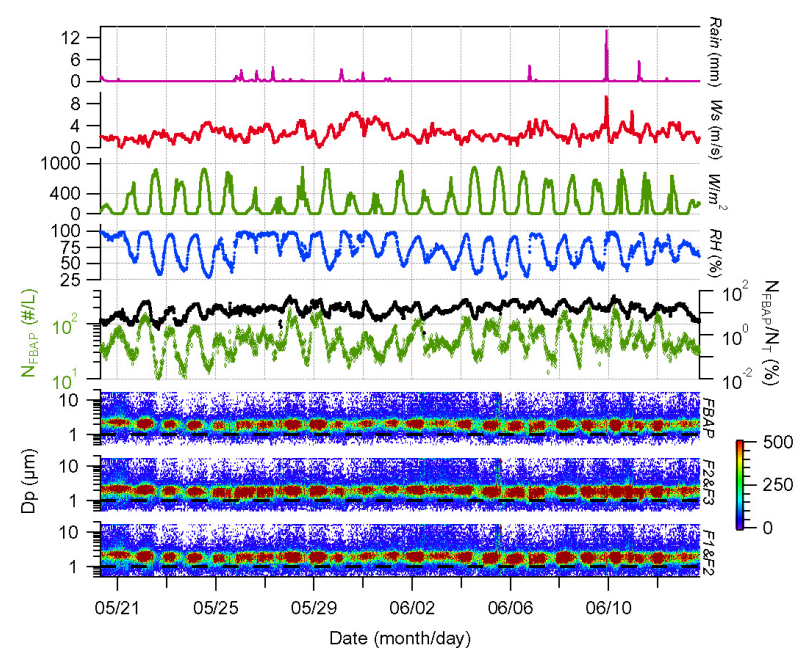

Fig. 12. WIBS-4 fluorescence data for a selected time period during spring season in comparison with meteorological data measured at the same time. The lower panels represent different combinations of fluorescent channels (F1\&F2: FL1_280 \& FL2_280, F2\&F3: FL2_280 \& FL2_370, FBAP: FL1_280 \& FL2_370). The upper panels show, from bottom to top, number concentration of FBAP (left) and ratio of FBAP to all particles (right) measured by WIBS $(0.8-16 \mu \mathrm{m})$, relative humidity $(\%)$, global solar radiation $\left(\mathrm{W} \mathrm{m}^{-2}\right)$, wind speed $\left(\mathrm{m} \mathrm{s}^{-1}\right)$, and precipitation $(\mathrm{mm})$.

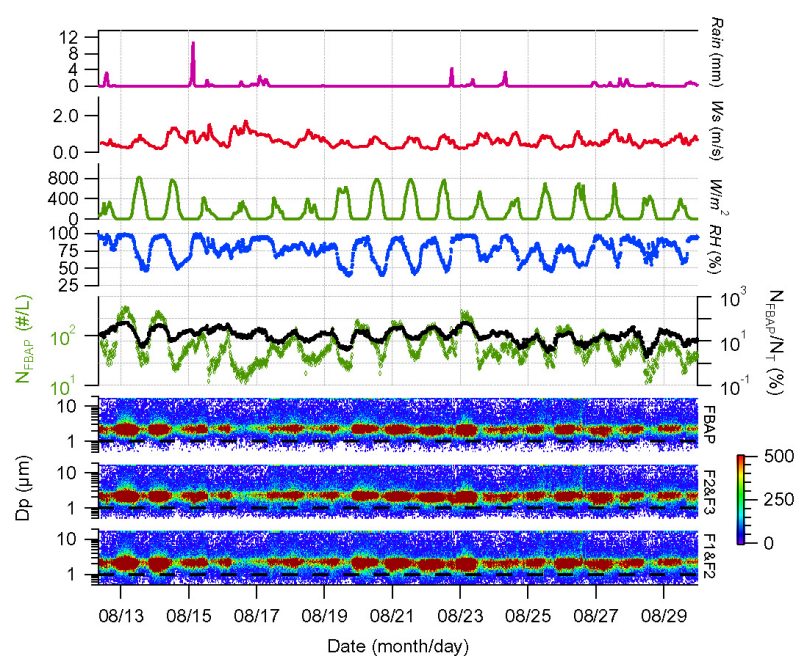

Fig. 13. WIBS-4 fluorescence data for a selected time period during summer season in comparison with meteorological data measured at the same time. The data were plotted in the same way as in Fig. 12.

global solar radiation) with warm and dry days and cool and humid nights (i.e. between 22 May-25 May). For these periods we observed a continuous release of biological aerosol particles during nighttime, which is apparently triggered by the highly humid conditions. This kind of biological aerosol release was investigated by several groups in the literature. For instance, Hirst (1953) found a direct relation between 


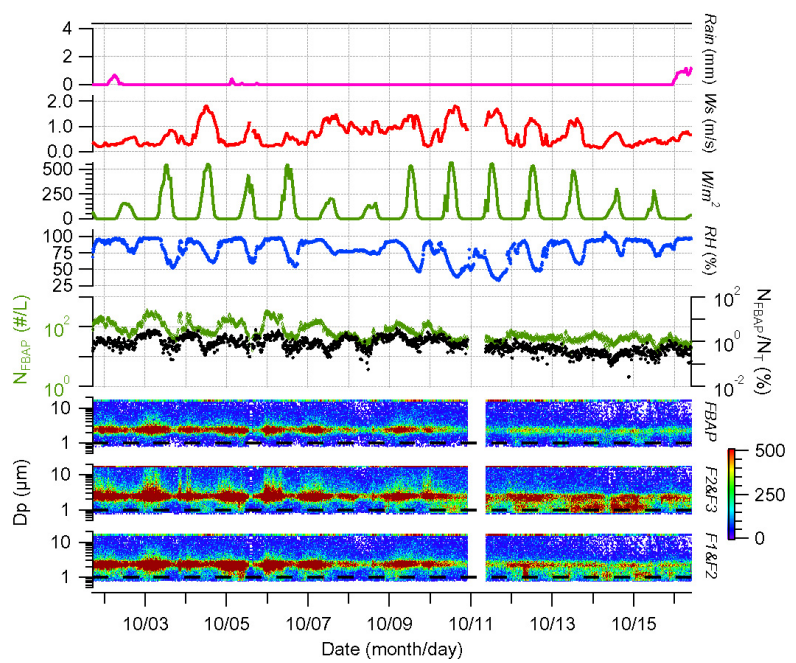

Fig. 14. WIBS-4 fluorescence data for a selected time period during autumn season in comparison with meteorological data measured at the same time. The data were plotted in the same way as in Fig. 12.

Basidiomycota (BMC) type of fungal spore release and relative humidity. This type of fungus ejects its spores according to an active mechanism and the ambient relative humidity is the key factor (Pringle et al., 2005; Elbert et al., 2007).

We performed a statistical analysis of the data to quantify the correlation between the FBAP number concentration and the relative humidity. Mean and median FBAP number concentration values were compared with the relative humidity values, which were measured at the same time, and FBAP numbers falling into $1 \%$ relative humidity bins were calculated. The resulting curves were then fitted according to a power law function. The coefficients of determination $\left(R^{2}\right)$ for the non-linear regressions were also calculated and reported. Figure 16 represents the correlation between $N_{\mathrm{FBAP}}$ and relative humidity for the four seasons. This figure clearly shows that the FBAP number concentration increased exponentially for relative humidity conditions higher than about $75 \%$ until $98 \%$. Our finding is in good agreement with the results published by Gabey et al. (2010). As a conclusion of this correlation, we can also speculate that our results are consistent with the well-known behavior of Basidiomycota (BMC) type of fungal spores, which are released mostly during nighttime and under humid conditions. However, under the light of our findings it is not possible to come to a conclusion about the spore type and the exact release mechanism of these particles.

Fröhlich-Nowoisky et al. (2012) presented the DNA-based analysis of airborne fungi in continental, coastal and marine air. They concluded that the BMC dominate continental air, while Ascomycota (AMC) prevails mostly in marine and coastal air. They also showed that most of the BMC species detected in continental, coastal and marine air belong to a single taxonomic class, the Agaricomycetes. A clear

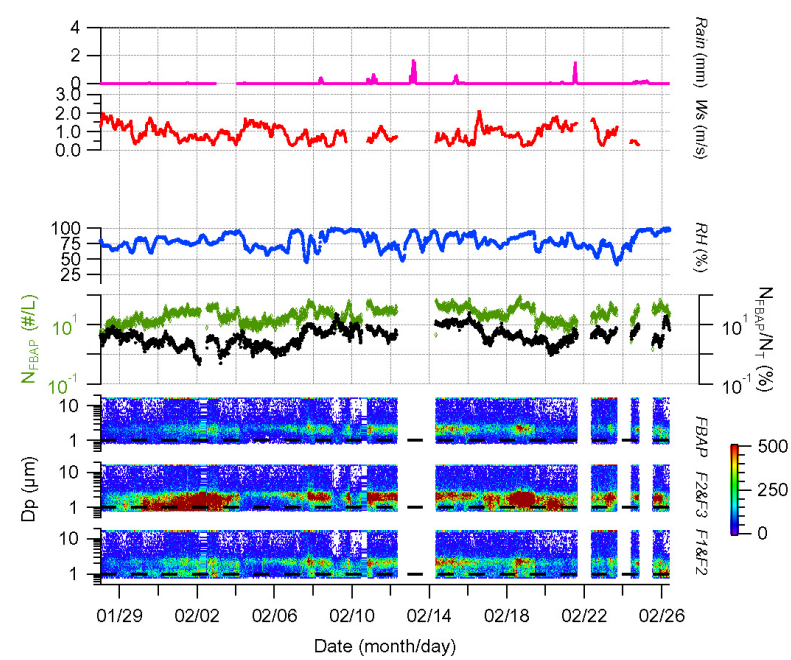

Fig. 15. WIBS-4 fluorescence data for a selected time period during winter season in comparison with meteorological data measured at the same time. The data were plotted in the same way as in Fig. 12.

identification of this kind of spore release would be possible by collecting filter samples and analyzing these samples with electron microscopy and DNA-based techniques in order to specify the spore type. The polymerase chain reaction (PCR) method, for instance, makes it possible to identify specific types of fungal species (Alvarez, 1995; Zhou et al., 2000; Fröhlich-Nowoisky et al., 2009, 2012; Lang-Yona et al., 2012). This will be performed in follow-up studies, but is beyond the scope of this work. On the other hand, we did not find any evidence of passive bioaerosol release, which is generally related to the wind speed and wind direction or precipitation. However, in some cases slightly increased FBAP number concentrations were observed following rain events.

\subsubsection{Size dependence of the FBAP/TAP ratio}

Another valuable result of this study is quantifying the size dependence of the relative contribution of FBAP to TAP. Figure 17 illustrates the relative contribution of FBAP number concentration to TAP for four sampling terms. By following the study published by Huffman et al. (2010), we integrated our data as 20-min time intervals, which corresponds to a total air volume of $\sim 5 \mathrm{~L}$. By following the statistical calculation used by Huffman et al. (2010), we assumed that WIBS-4 should be able to detect at least one biological particle in $5 \mathrm{~L}$ of sampled air. Huffman et al. (2010) reported the number ratio of FBAP to TAP to be less than $10 \%$ for the fine particulate matter $\left(1.0 \mu \mathrm{m}<D_{\mathrm{a}}<2.5 \mu \mathrm{m}\right.$, aerodynamic size $)$ in Mainz, Germany. For the same seasonal period and including almost the same size range, WIBS- 4 measured about $20 \%$ contribution (Fig. 17c). Overlapping of the median and the mean curves on these ratio plots asserts the good counting statistics of the instrument. A deviation from this overlapping 

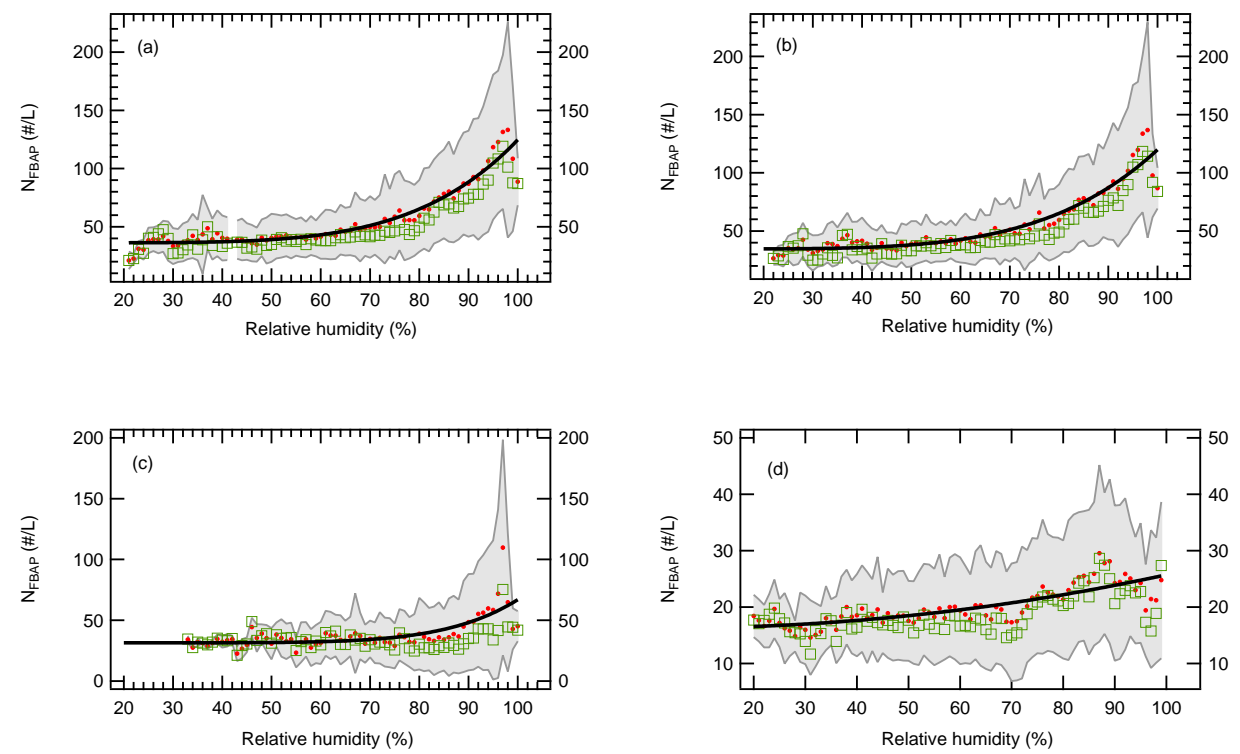

Fig. 16. Correlation of the WIBS-4 FBAP number concentrations with the relative humidity; red markers show mean FBAP concentration $\left(N_{\mathrm{FBAP}}, \# / \mathrm{L}\right)$, green markers show median $N_{\mathrm{FBAP}}$, solid black lines represent fitted curve according to the mean $N_{\mathrm{FBAP}}$, grey shaded areas represent variability of FBAP concentration as plus-minus standard deviations. Fit function: $f(x)=a \cdot x^{b}+c ;\left(\right.$ a) $\operatorname{spring}\left(R^{2}=0.924\right)$, (b) summer $\left(R^{2}=0.911\right)$, (c) autumn $\left(R^{2}=0.541\right)$, (d) winter $\left(R^{2}=0.652\right)$.

could be because of the low counting statistics, which is reflected on median curves for bigger particles.

In the spring period, we observed one broadened peak around $3 \mu \mathrm{m}$ (Fig. 17a), which is reflected by both median and the mean ratio curves. For the coarse mode particles the median ratio curve dropped gradually after this peak, while the mean ratio curve increased for the bigger particles. The decrease of the median ratio curve in this period can be explained also by low counting statistics, which forces the median towards zero. $N_{\mathrm{FBAP}} N_{\mathrm{T}}^{-1}$ was calculated as $\sim 30 \%$ for the fine particles ( $D_{\mathrm{p}}<2.5 \mu \mathrm{m}$, optical size) in this season. Median and mean ratio curves differed for particle sizes larger than $\sim 3 \mu \mathrm{m}$, which shows that during spring term the FBAP population was dominated by small particles. In the summer period, the median ratio curve shows a different behavior compared to the spring period (Fig 17b), whereas the mean ratio curve has preserved almost the same trend. The median ratio curve maximum position is shifted to slightly larger sizes and, therefore, the counting statistics were obviously better for larger particles compared to the spring period. The $N_{\mathrm{FBAP}} N_{\mathrm{T}}^{-1}(\%)$ was calculated as $\sim 30 \%$ for fine mode particles and $\sim 40 \%$ for the coarse mode particles. During the autumn period (Fig. 17c), a similar pattern was observed with a small shift of the median curve maximum. $N_{\mathrm{FBAP}} N_{\mathrm{T}}^{-1}(\%)$ was found to be around $20 \%$ for fine particles and between $30-40 \%$ for coarse mode particles. These observations show that the coarse mode of the FBAP population was significantly increased in the summer and au- tumn seasons compared to the spring, which indicates the release of additional larger bioaerosol particles (e.g. spores and pollens) in these periods. It can clearly be seen that during the winter season (Fig. 17d), the relative contribution of FBAP to TAP was decreased to around $15 \%$ for fine particles, which represents the lowest background FBAP concentration present during all year. However, the coarse mode FBAP contribution was between $20-50 \%$ and, thus, comparable to the other seasons.

\section{Conclusions and outlook}

In this paper, we presented several laboratory tests and a oneyear online measurement of ambient aerosol by using the UV-LIF method in a semi-urban area at Karlsruhe Institute of Technology (KIT), Campus North, Germany. For this purpose, a recently developed single particle bioaerosol sensor (WIBS-4) was used. To our knowledge, this study is the first long-term usage of WIBS in a field campaign that provides insight into the capabilities of this instrument for analyzing the seasonal variations of fluorescent biological aerosol particles (FBAP) in the atmospheric aerosol. Laboratory measurements supported and clarified the accuracy of defined threshold to discriminate the biological from non-biological aerosols. As a final conclusion of these laboratory tests, we can indicate that, although there are particles which fluoresce and interfere in this method, the use of the combination of two fluorescence channels provides a good discrimination 

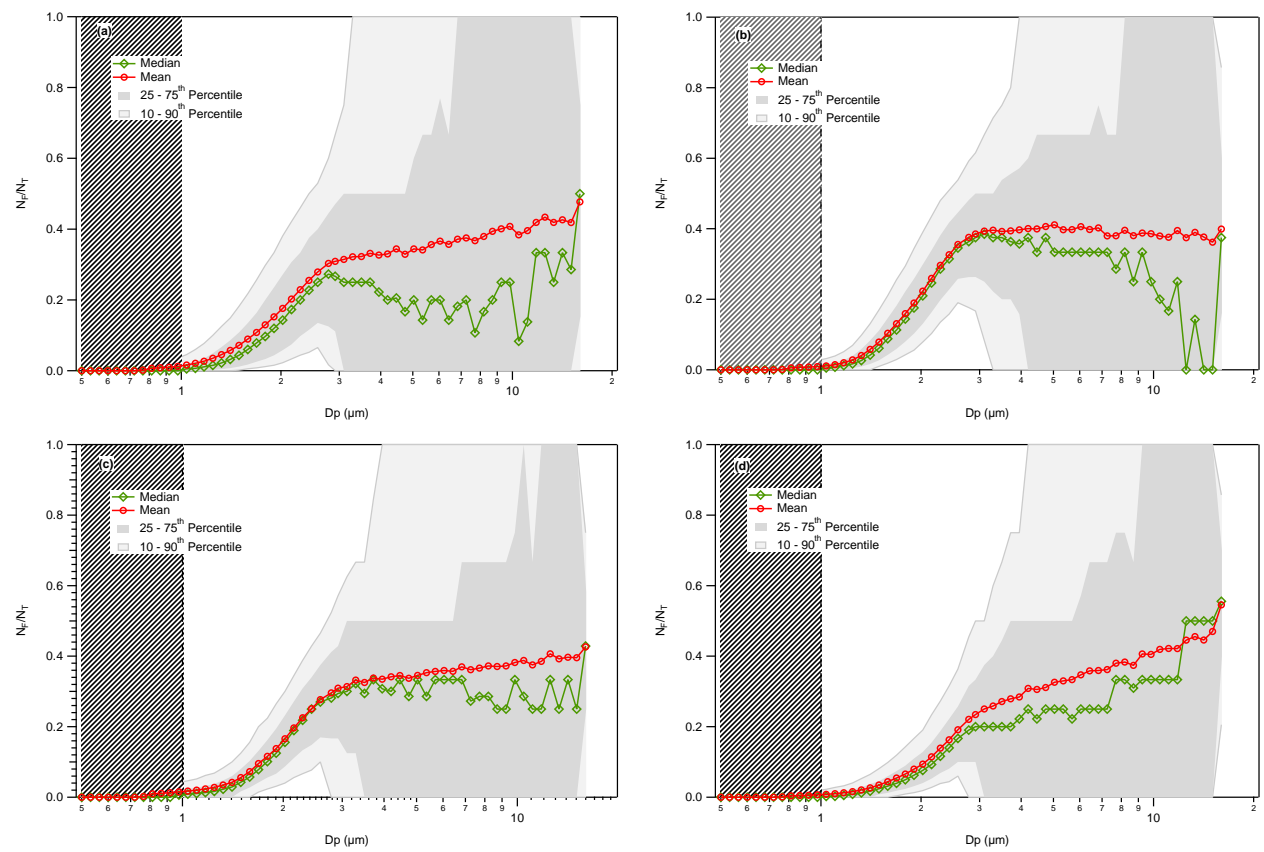

Fig. 17. Fluorescence ratio distribution for different seasons: (a) spring, (b) summer, (c) autumn, (d) winter. Left axis indicates the ratio of number of fluorescent particles to total particles for different size bins. The hatched area represents the particles smaller than $1 \mu \mathrm{m}$. The reader should keep in mind that those particles may refer to non-biological fluorescent aerosol (Huffman et al., 2010).

of biological aerosol. For example, the ammonium sulphate aerosol that prevails in the ambient air can be easily differentiated by this method. Furthermore, it is also possible to distinguish biological aerosol from mineral dust, which is an important component of the atmospheric aerosol and affects atmospheric processes in several ways. A low cross sensitivity of the used biological aerosol definition (F1 and F3) in the case of CAST soot aerosol was also observed. However, the contribution was only around $0.2 \%$. In future studies, other measurement parameters like the particle asymmetry factor can be exploited to provide an even better discrimination of biological aerosol.

FBAP were observed during the entire sampling period. FBAP number concentrations increased gradually from spring to summer and decreased in the same manner towards the end of autumn and reached a minimum value in winter. Fluorescent biological aerosol particle number concentration was between $10-53 \mathrm{~L}^{-1}\left(\right.$ mean $\left.=29 \mathrm{~L}^{-1}\right)$ and $20-80 \mathrm{~L}^{-1}\left(\right.$ mean $\left.=46 \mathrm{~L}^{-1}\right)$ in spring and summer, respectively. In autumn and winter, $N_{\text {FBAP }}$ was between $8-54 \mathrm{~L}^{-1}$ $\left(\right.$ mean $\left.=29 \mathrm{~L}^{-1}\right)$ and $8-32 \mathrm{~L}^{-1}\left(\right.$ mean $\left.=31 \mathrm{~L}^{-1}\right)$, respectively. In spring and summer, the relative contribution of FBAP to the total aerosol particle (TAP) varied between $0.26-40 \%(\operatorname{mean}=7 \%)$ and $0.90-42 \% \quad($ mean $=11 \%)$, while in autumn and winter the ratio varied between 0.32 $30 \%($ mean $=7 \%)$ and $0.43-18 \%($ mean $=4 \%)$, respectively.
The correlation of the WIBS fluorescence measurements with meteorological data showed a strong relation of the FBAP number concentrations with the relative humidity. Measured wind data were also presented on the same plot (Fig. 12). However, FBAP concentrations changed independently of the wind speed and the wind direction. For most of the time, FBAP was dominated by one distinct mode of particles, which appeared between 2 to $3 \mu \mathrm{m}$ and which we attribute to a site-specific spore type. Although a detailed speciation is not possible with the UV-LIF method, the fact that this FBAP mode shows a strong correlation with the relative humidity, which reveals an effective release mechanism during humid clear-sky nights, points toward a wet actively discharged fungal spore (Elbert et al., 2007).

All published studies about the rapid detection of primary biological aerosol particles using the UV-LIF method were limited because of the well-known interference from nonbiological fluorescent aerosol that is a certain amount of the total aerosol. To our knowledge, this is the first study that combines laboratory experiments with long-term field studies in order to quantify these possible interferences. The presented results motivate us to conduct further long-term field measurements at different locations using the WIBS-4 instrument. Nevertheless, we need a better understanding of how the fluorescence of biological aerosols changes under different conditions like mechanical stress and heat, humidity, aging, etc. Including all these parameters, new laboratory experiments need to be designed and different relevant 
biological and non-biological aerosol samples should be investigated. In this way and exploiting the additional information from the shape sensitive detector of WIBS-4, it should be possible to define a robust discrimination method that provides a better discrimination of biological ambient aerosol under different atmospheric conditions.

Acknowledgements. This work was funded by the Graduate School for Climate and Environment (GRACE) at KIT and the HelmholtzGemeinschaft Deutscher Forschungszentren as part of the program "Atmosphere and Climate". The authors thank Corinna Hoose for the fruitful discussions and her review of the manuscript. We gratefully acknowledge support by Paul $\mathrm{H}$. Kaye and his team at the University of Hertfordshire for building WIBS-4 instrument and their outstanding support. Thanks are dedicated to Claudia Linke, Olga Dombrowski, Georg Scheurig, and Rainer Buschbacher for their support during the laboratory tests. We thank David Healy for the spore sample used in the laboratory experiments. Andy Gabey is thanked for providing us with his Matlab analysis program and for his support to adapt it to WIBS-4. We thank Martin Kohler for the data from the meteorological tower. We acknowledge support by Deutsche Forschungsgemeinschaft and Open Access Publishing Fund of Karlsruhe Institute of Technology.

The service charges for this open access publication have been covered by a Research Centre of the Helmholtz Association.

Edited by: M. Gysel

\section{References}

Alvarez, A. J., Buttner, M. P., and Stetzenbach, L. D.: PCR for bioaerosol monitoring: sensitivity and environmental interference, Appl. Environ. Microbiol., 61, 3639-3644, 1995.

Bauer, H., Kasper-Giebl, A., Loflund, M., Giebl, H., Hitzenberger, R., Zibuschka, F., and Puxbaum, H.: The contribution of bacteria and fungal spores to the organic carbon content of cloud water, precipitation and aerosols, Atmos. Res., 64, 109-119, 2002.

Bauer, H., Claeys, M., Vermeylen, R., Schueller, E., Weinke, G., Berger, A., and Puxbaum, H.: Arabitol and mannitol as tracers for the quantification of airborne fungal spores, Atmos. Environ., 42, 588-593, doi:10.1016/j.atmosenv.2007.10.013, 2008.

Brosseau, L. M., Vesley, D., Rice, N., Goodell, K., Nellis, M., and Hairston, P.: Differences in detected fluorescence among several bacterial species measured with a direct-reading particle sizer and fluorescence detector, Aerosol Sci. Tech., 32, 545-558, 2000.

Burrows, S. M., Butler, T., Jöckel, P., Tost, H., Kerkweg, A., Pöschl, U., and Lawrence, M. G.: Bacteria in the global atmosphere - Part 2: Modeling of emissions and transport between different ecosystems, Atmos. Chem. Phys., 9, 9281-9297, doi:10.5194/acp-9-9281-2009, 2009.

Christner, B. C., Morris, C. E., Foreman, C. M., Cai, R., and Sands, D. C.: Ubiquity of biological ice nucleators in snowfall, Science, 319, 1214, doi:10.1126/science.1149757, 2008.

Cooke, W. F., Liousse, C., Cachier, H., and Feichter, J.: Construction of a 1 degrees $\times 1$ degrees fossil fuel emission data set for carbonaceous aerosol and implementation and radiative impact in the ECHAM4 model, J. Geophys. Res.-Atmos., 104, 2213722162, 1999.

Crawford, C., Reponen, T., Lee, T., Iossifova, Y., Levin, L., Adhikari, A., and Grinshpun, S. A.: Temporal and spatial variation of indoor and outdoor airborne fungal spores, pollen, and $(1 \rightarrow 3)$ $\beta$-d-glucan, Aerobiologia, 25, 147-158, doi:10.1007/s10453009-9120-z, 2009.

De Antoni Zoppas, B. C., Valencia-Barrera, R. M., Vergamini Duso, S. M., and Fernández-González, D.: Fungal spores prevalent in the aerosol of the city of Caxias do Sul, Rio Grande do Sul, Brazil, over a 2-year period (2001-2002), Aerobiologia, 22, 117124, doi:10.1007/s10453-006-9022-2, 2006.

Despres, V. R., Huffman, J. A., Burrows, S. M., Hoose, C., Safatov, A. S., Buryak, G., Fröhlich-Nawoisky, J., Elbert, W., Andreae, M. O., Pöschl, U., and Jaenicke, R.: Primary Biological Aerosol Particles in the Atmosphere: A Review, Tellus B, 64, 15598, doi:10.3402/tellusb.v64i0.15598, 2012.

Diehl, K., Quick, C., Matthias-Maser, S., Mitra, S. K., and Jaenicke, R.: The ice nucleating ability of pollen - Part I: Laboratory studies in deposition and condensation freezing modes, Atmos. Res., 58, 75-87, 2001.

Diehl, K., Matthias-Maser, S., Jaenicke, R., and Mitra, S. K.: The ice nucleating ability of pollen: Part II. Laboratory studies in immersion and contact freezing modes, Atmos. Res., 61, 125-133, 2002.

Elbert, W., Taylor, P. E., Andreae, M. O., and Pöschl, U.: Contribution of fungi to primary biogenic aerosols in the atmosphere: wet and dry discharged spores, carbohydrates, and inorganic ions, Atmos. Chem. Phys., 7, 4569-4588, doi:10.5194/acp-7-4569-2007, 2007.

Eversole, J. D., Cary, W. K., Scotto, C. S., Pierson, R., Spence, M., and Campillo, A. J.: Continuous bioaerosol monitoring using UV excitation fluorescence: Outdoor test results, Field Anal. Chem. Tech., 5, 205-212, 2001.

Foot, V. E., Kaye, P. H., Stanley, W. R., Barrington, S. J., Gallagher, M., and Gabey, A.: Low-cost real-time multiparameter bio-aerosol sensors, Optically Based Biological and Chemical Detection for Defence IV, Cardiff, Wales, UK, 71160I-71112, 2008

Fröhlich-Nowoisky, J., Pickersgill, D. A., Després, V. R., and Pöschl, U.: High diversity of fungi in air particulate matter, P. Natl. Acad. Sci. USA, 106, 12814-12819, doi:10.1073/pnas.0811003106, 2009.

Fröhlich-Nowoisky, J., Burrows, S. M., Xie, Z., Engling, G., Solomon, P. A., Fraser, M. P., Mayol-Bracero, O. L., Artaxo, P., Begerow, D., Conrad, R., Andreae, M. O., Després, V. R., and Pöschl, U.: Biogeography in the air: fungal diversity over land and oceans, Biogeosciences, 9, 1125-1136, doi:10.5194/bg9-1125-2012, 2012.

Gabey, A. M.: Laboratory and field characterisation of fluorescent and primary biological aerosol particles, Ph.D., University of Manchester, 2011.

Gabey, A. M., Gallagher, M. W., Whitehead, J., Dorsey, J. R., Kaye, P. H., and Stanley, W. R.: Measurements and comparison of primary biological aerosol above and below a tropical forest canopy using a dual channel fluorescence spectrometer, Atmos. Chem. Phys., 10, 4453-4466, doi:10.5194/acp-10-4453-2010, 2010. 
Gabey, A. M., Stanley, W. R., Gallagher, M. W., and Kaye, P. H.: The fluorescence properties of aerosol larger than $0.8 \mu \mathrm{m}$ in urban and tropical rainforest locations, Atmos. Chem. Phys., 11, 5491-5504, doi:10.5194/acp-11-5491-2011, 2011.

Garland, R. M., Yang, H., Schmid, O., Rose, D., Nowak, A., Achtert, P., Wiedensohler, A., Takegawa, N., Kita, K., Miyazaki, Y., Kondo, Y., Hu, M., Shao, M., Zeng, L. M., Zhang, Y. H., Andreae, M. O., and Pöschl, U.: Aerosol optical properties in a rural environment near the mega-city Guangzhou, China: implications for regional air pollution, radiative forcing and remote sensing, Atmos. Chem. Phys., 8, 5161-5186, doi:10.5194/acp-85161-2008, 2008.

Garland, R. M., Schmid, O., Nowak, A., Achtert, P., Wiedensohler, A., Gunthe, S. S., Takegawa, N., Kita, K., Kondo, Y., Hu, M., Shao, M., Zeng, L. M., Zhu, T., Andreae, M. O., and Pöschl, U.: Aerosol optical properties observed during Campaign of Air Quality Research in Beijing 2006 (CAREBeijing2006): Characteristic differences between the inflow and outflow of Beijing city air, J. Geophys. Res.-Atmos., 114, D00G04, doi:10.1029/2008jd010780, 2009.

Gilbert, G. S.: Nocturnal Fungi: Airborne Spores in the Canopy and Understory of a Tropical Rain Forest, Biotropica, 37, 462-464, 2005

Gilbert, G. S. and Reynolds, D. R.: Nocturnal Fungi: Airborne Spores in the Canopy and Understory of a Tropical Rain Forest, Biotropica, 37, 462-464, 2005.

Gregory, P. H. and Hirst, J. M.: The Summer Air-Spora at Rothamsted in 1952, J Gen. Microbiol, 17, 135-152, 1957.

Gruber, S., Matthias-Maser, S., and Jaenicke, R.: Concentration and Chemical Composition of Aerosol Particles in Marine and Continental Air, J. Aerosol Sci., 30, S9-S10, 1999.

Hairston, P. P., Ho, J., and Quant, F. R.: Design of an instrument for real-time detection of bioaerosols using simultaneous measurement of particle aerodynamic size and intrinsic fluorescence, J. Aerosol Sci, 28, 471-482, 1997.

Hallar, A. G., Chirokova, G., McCubbin, I., Painter, T. H., Wiedinmyer, C., and Dodson, C.: Atmospheric bioaerosols transported via dust storms in the western United States, Geophys. Res. Lett., 38, L17801, doi:10.1029/2011GL048166, 2011.

Healy, D. A., O'Connor, D. J., and Sodeau, J. R.: Measurement of the particle counting efficiency of the "Waveband Integrated Bioaerosol Sensor" model number 4 (WIBS-4), J. Aerosol Sci., 47, 94-99, doi:10.1016/j.jaerosci.2012.01.003, 2012a.

Healy, D. A., O'Connor, D. J., Burke, A. M., and Sodeau, J. R.: A laboratory assessment of the Waveband Integrated Bioaerosol Sensor (WIBS-4) using individual samples of pollen and fungal spore material, Atmos. Environ., 60, 534-543, doi:10.1016/j.atmosenv.2012.06.052, 2012b.

Hill, S. C., Pinnick, R. G., Niles, S., Pan, Y.-L., Holler, S., Chang, R. K., Bottiger, J., Chen, B. T., Orr, C.-S., and Feather, G.: Real-time measurement of fluorescence spectra from single airborne biological particles, Field Anal. Chem. Technol., 3, 221-239, 1999.

Hill, S. C., Pinnick, R. G., Niles, S., Fell, N. F., Pan, Y.-L., Bottiger, J., Bronk, B.V., Holler, S., and Chang, R. K.: Fluorescence from Airborne Microparticles: Dependence on Size, Concentration of Fluorophores, and Illumination Intensity, Appl. Optics, 40, 3005-3013, 2001.

Hirst, J. M.: Changes in atmospheric spore content: Diurnal periodicity and the effects of weather, Trans. Brit. Mycol. Soc., 36,
375-393, 1953.

Hirst, E., Kaye, P. H., Greenaway, R. S., Field, P., and Johnson, D. W.: Discrimination of micrometre-sized ice and super-cooled droplets in mixed-phase cloud, Atmos. Environ., 35, 33-47, 2001.

Ho, J.: Future of biological aerosol detection, Analytica Chimica Acta, 457, 125-148, 2002.

Huffman, J. A., Treutlein, B., and Pöschl, U.: Fluorescent biological aerosol particle concentrations and size distributions measured with an Ultraviolet Aerodynamic Particle Sizer (UVAPS) in Central Europe, Atmos. Chem. Phys., 10, 3215-3233, doi:10.5194/acp-10-3215-2010, 2010.

Jaenicke, R., Matthias-Maser, S., and Gruber, S.: Omnipresence of biological material in the atmosphere, Environ. Chem., 4, 217 220, doi:10.1071/en07021, 2007.

Kaye, P. H., Stanley, W. R., Hirst, E., Foot, E. V., Baxter, K. L., and Barrington, S. J.: Single particle multichannel bio-aerosol fluorescence sensor, Opt. Express, 13, 3583-3593, 2005.

Kaye, P. H., Aptowicz, K., Chang, R. K., Foot, V., and Videen, G.: Angularly resolved elastic scattering from airborne particles Potential for characterizing, classifying, and identifying individual aerosol particles, Opt. Biol. Part., 238, 31-61, 2007.

Lang-Yona, N., Dannemiller, K., Yamamoto, N., Burshtein, N., Peccia, J., Yarden, O., and Rudich, Y.: Annual distribution of allergenic fungal spores in atmospheric particulate matter in the Eastern Mediterranean; a comparative study between ergosterol and quantitative PCR analysis, Atmos. Chem. Phys., 12, 2681-2690, doi:10.5194/acp-12-2681-2012, 2012.

Matthias-Maser, S. and Jaenicke, R.: The size distribution of primary biological aerosol particles with radii $>0.2 \mu \mathrm{m}$ in an urban/rural influenced region, Atmos. Res., 39, 279-286, 1995.

Matthias-Maser, S., Peters, K., and Jaenicke, R.: Seasonal Variation of Primary Biological Aerosol Particles, J. Aerosol Sci., 26, S545-S546, 1995.

Matthias-Maser, S., Reichert, K., and Jaenicke, R.: Primary Biological Aerosol Particles at the High Alpine Site of Jungfraujoch/Switzerland, J. Aerosol Sci., 31, S955-S956, 2000.

Monks, P. S., Granier, C., Fuzzi, S., Stohl, A., Williams, M. L., Akimoto, H., Amann, M., Baklanov, A., Baltensperger, U., Bey, I., Blake, N., Blake, R. S., Carslaw, K., Cooper, O. R., Dentener, F., Fowler, D., Fragkou, E., Frost, G. J., Generoso, S., Ginoux, P., Grewe, V., Guenther, A., Hansson, H. C., Henne, S., Hjorth, J., Hofzumahaus, A., Huntrieser, H., Isaksen, I. S. A., Jenkin, M. E., Kaiser, J., Kanakidou, M., Klimont, Z., Kulmala, M., Laj, P., Lawrence, M. G., Lee, J. D., Liousse, C., Maione, M., McFiggans, G., Metzger, A., Mieville, A., Moussiopoulos, N., Orlando, J. J., O’Dowd, C. D., Palmer, P. I., Parrish, D. D., Petzold, A., Platt, U., Pöschl, U., Prévôt, A. S. H., Reeves, C. E., Reimann, S., Rudich, Y., Sellegri, K., Steinbrecher, R., Simpson, D., ten Brink, H., Theloke, J., van der Werf, G. R., Vautard, R., Vestreng, V., Vlachokostas, C., and von Glasow, R.: Atmospheric composition change - global and regional air quality, Atmos. Environ., 43, 5268-5350, doi:10.1016/j.atmosenv.2009.08.021, 2009.

Morris, C. E. and Kinkel, L. L.: Fifty years of phyllosphere microbiology: significant contributions to research in related fields, in: Phyllosphere Microbiology, edited by: Lindow, S. E., HechtPoinar, E. I., and Elliot, V. J., APS Press, MN, 365-375, 2002.

Möhler, O., Field, P. R., Connolly, P., Benz, S., Saathoff, H., Schnaiter, M., Wagner, R., Cotton, R., Krämer, M., Mangold, A. 
and Heymsfield, A. J.: Efficiency of the deposition mode ice nucleation on mineral dust particles, Atmos. Chem. Phys., 6, 30073021, doi:10.5194/acp-6-3007-2006, 2006.

Pan, Y.-L., Pinnick, R. G., Hill, S. C., Rosen, J. M., and Chang, R. K.: Single-particle laser-induced-fluorescence spectra of biological and other organic-carbon aerosols in the atmosphere: Measurements at New Haven, Connecticut, and Las Cruces, New Mexico, J. Geophys. Res., 112, D24S19, doi:10.1029/2007jd008741, 2007.

Petters, M. D. and Kreidenweis, S. M.: A single parameter representation of hygroscopic growth and cloud condensation nucleus activity, Atmos. Chem. Phys., 7, 1961-1971, doi:10.5194/acp-71961-2007, 2007.

Pinnick, R. G., Hill, S. C., Nachman, P., Pendleton, J. D., Fernandez, G. L., Mayo, M. W., and Bruno, J. G.: Fluorescence Particle Counter for Detecting Airborne Bacteria and Other Biological Particles, Aerosol Sci. Tech., 23, 653-664, doi:10.1080/02786829508965345, 1998.

Pöhlker, C., Huffman, J. A., and Pöschl, U.: Autofluorescence of atmospheric bioaerosols - fluorescent biomolecules and potential interferences, Atmos. Meas. Tech., 5, 37-71, doi:10.5194/amt-537-2012, 2012.

Pöschl, U.: Atmospheric aerosols: composition, transformation, climate and health effects, Angew. Chem. Int. Edit., 44, 7520-7540, doi:10.1002/anie.200501122, 2005.

Pringle, A., Patek, S. N., Fischer, M., Stolze, J., and Money, N. P.: The captured launch of a ballistospore, Mycologia, 97, 866-871, 2005.

Robinson, N. H., Allan, J. D., Huffman, J. A., Kaye, P. H., Foot, V. E., and Gallagher, M.: Cluster analysis of WIBS single particle bioaerosol data, Atmos. Meas. Tech. Discuss., 5, 6387-6422, doi:10.5194/amtd-5-6387-2012, 2012.

Rosenfeld, D., Lohmann, U., Raga, G. B., O’Dowd, C. D., Kulmala, M., Fuzzi, S., Reissell, A., and Andreae, M. O.: Flood or drought: how do aerosols affect precipitation?, Science, 321, 1309-1313, doi:10.1126/science.1160606, 2008.

Sánchez-Ochoa, A., Kasper-Giebl, A., Puxbaum, H., Gelencser, A., Legrand, M., and Pio, C.: Concentration of atmospheric cellulose: A proxy for plant debris across a westeast transect over Europe, J. Geophys. Res., 112, D23S08, dooi:10.1029/2006jd008180, 2007.
Schauer, C., Niessner, R., and Pöschl, U.: Analysis of nitrated polycyclic aromatic hydrocarbons by liquid chromatography with fluorescence and mass spectrometry detection: air particulate matter, soot, and reaction product studies, Anal. Bioanal. Chem., 378, 725-736, doi:10.1007/s00216-003-2449-1, 2004.

Schnaiter, M., Gimmler, M., Llamas, I., Linke, C., Jäger, C., and Mutschke, H.: Strong spectral dependence of light absorption by organic carbon particles formed by propane combustion, Atmos. Chem. Phys., 6, 2981-2990, doi:10.5194/acp-6-2981-2006, 2006.

Smith, D. J., Griffin, D. W., and Jaffe, D. A.: The High Life: Transport of Microbes in the Atmosphere, EOS, Transactions, American Geophysical Union, 92, 249-256, 2011.

Stanley, W. R., Kaye, P. H., Foot, V. E., Barrington, S. J., Gallagher, M., and Gabey, A.: Continuous bioaerosol monitoring in a tropical environment using a UV fluorescence particle spectrometer, Atmos. Sci. Lett., 12, 195-199, doi:10.1002/asl.310, 2011.

Winiwarter, W., Bauer, H., Caseiro, A., and Puxbaum, H.: Quantifying emissions of primary biological aerosol particle mass in Europe, Atmos. Environ., 43, 1403-1409, 2009.

Womiloju, T. O., Miller, J. D., Mayer, P. M., and Brook, J. R.: Methods to determine the biological composition of particulate matter collected from outdoor air, Atmos. Environ., 37, 4335-4344, doi:10.1016/s1352-2310(03)00577-6, 2003.

Wu, P. C., Tsai, J. C., Li, F. C., Lung, S. C., and Su, H. J.: Increased levels of ambient fungal spores in Taiwan are associated with dust events from China, Atmos. Environ., 38, 4879-4886, doi:10.1016/j.atmosenv.2004.05.039, 2004.

Yadav, R. K. P., Halley, J. M., Karamanoli, K., Constantinidou, H. I., and Vokou, D.: Bacterial populations on the leaves of Mediterranean plants: quantitative features and testing of distribution models, Environ. Exp. Botany, 52, 63-77, doi:10.1016/j.envexpbot.2004.01.004, 2004.

Zhou, G., Whong,W. Z., and Ong, T.: Development of a fungusspecific PCR assay for detecting low-level fungi in an indoor environment, Molec. Cell. Probe, 14, 339-348, 2000. 